\title{
Dopamine modulation of learning and memory in the prefrontal cortex: insights from studies in primates, rodents, and birds
}

\author{
M. Victoria Puig ${ }^{1}{ }^{*}$, Jonas Rose ${ }^{1,2}{ }^{*}$, Robert Schmidt ${ }^{3}$ and Nadja Freund ${ }^{4}$ \\ 'The Picower Institute for Learning and Memory, Department of Brain and Cognitive Sciences, Massachusetts Institute of Technology, Cambridge, MA, USA \\ ${ }^{2}$ Animal Physiology, Institute of Neurobiology, University of Tübingen, Tübingen, Germany \\ ${ }^{3}$ BrainLinks-BrainTools, Department of Biology, Bernstein Center Freiburg, University of Freiburg, Freiburg, Germany \\ ${ }^{4}$ Department of Psychiatry and Psychotherapy, University of Tübingen, Tübingen, Germany
}

\section{Edited by:}

Guillermo Gonzalez-Burgos,

University of Pittsburgh, USA

\section{Reviewed by:}

Onur Gunturkun, Ruhr University Bochum, Germany

Min Wang, Yale University, USA

\section{${ }^{*}$ Correspondence:}

M. Victoria Puig and Jonas Rose, The

Picower Institute for Learning and

Memory, Department of Brain and

Cognitive Sciences, Massachusetts

Institute of Technology, Cambridge,

MA 02139, USA

e-mail:mvpuig@mit.edu
In this review, we provide a brief overview over the current knowledge about the role of dopamine transmission in the prefrontal cortex during learning and memory. We discuss work in humans, monkeys, rats, and birds in order to provide a basis for comparison across species that might help identify crucial features and constraints of the dopaminergic system in executive function. Computational models of dopamine function are introduced to provide a framework for such a comparison. We also provide a brief evolutionary perspective showing that the dopaminergic system is highly preserved across mammals. Even birds, following a largely independent evolution of higher cognitive abilities, have evolved a comparable dopaminergic system. Finally, we discuss the unique advantages and challenges of using different animal models for advancing our understanding of dopamine function in the healthy and diseased brain.

Keywords: prefrontal cortex, learning and memory, dopamine receptors, executive function, working memory, neuromodulation, evolution

\section{INTRODUCTION}

A major function of executive control is the flexible adaptation to our ever-changing environment. The executive circuits of the brain must, therefore, not only monitor and maintain current behavioral goals but also incorporate new goals and rules. This updating can come in the form of a quick integration of previously acquired knowledge when, for example, a well-known stimulus informs an animal of a change in reward contingencies. In many cases, however, such updating requires new learning, for example when a new stimulus is encountered for the first time. Executive functions are commonly ascribed to the prefrontal cortex (PFC) and frontostriatal networks. The function of these circuits relies heavily on neuromodulation, in particular on dopamine (DA). The aim of this review is to outline the contribution of DA and its receptors in the PFC to learning and memory processes across different species.

We will first introduce studies in the mammalian brain in the sections on humans, non-human primates, and rodents. Due to the challenges of investigating the role of DA transmission in human PFC, we focus the human section on studies utilizing systemic injections of DA agents and impairments of DA transmission in patients with a variety of neurological and psychiatric disorders. The non-human primate and rodent sections review behavioral studies conducted during local manipulations of the DA system in the PFC. While the dopaminergic system in different mammalian species follows largely the same organization, some conceptual and terminological differences can make a comparison of data across species difficult (Box 1). For a comparative perspective, we will then outline behavioral studies conducted in birds where local manipulations of the DA system were implemented in a structure equivalent to the mammal PFC, the nidopallium caudolaterale (NCL; Jarvis et al., 2005). Such a comparison is of particular interest given the large evolutionary gap between these species. The lines of birds and mammals separated around 300 million years ago, long before many of the cognitive functions attributed to the PFC evolved (Jarvis et al., 2005; Reiner et al., 2005; Jarvis, 2009; Rose et al., 2009a). In spite of this distance, birds and mammals (with the exception of humans and apes) are largely on par when it comes to cognitive abilities (Emery and Clayton, 2004; Kirsch et al., 2008, 2009). This implies a parallel or convergent evolution of cognition between the species (Emery and Clayton, 2004; Güntürkün, 2012). As a result of this independent evolution, we see stark differences in brain organization between birds and mammals (Jarvis et al., 2005). Most notably, the avian telencephalon does not show the laminar organization of the mammalian cortex. However, other organizational principles were preserved or evolved independently in both lines. This can be taken as a hint of narrow neurobiological constraints in the evolution of a given cognitive ability (Colombo and Broadbent, 2000; Güntürkün, 2005a).

\section{ANATOMY OF THE DOPAMINE SYSTEM IN THE PREFRONTAL CORTEX}

The anatomy of the dopaminergic system is very similar between all mammals and birds (for extensive review, see Durstewitz et al., 1998, 1999b; Björklund and Dunnett, 2007). DA neurons can be identified by the expression of several catecholamine-synthesizing 


\section{BOX 1 | Conceptual/terminological differences between species.}

When comparing the function of prefrontal DA across species it is important to clarify the terminology used in the different fields of research. As reviewed here, prefrontal DA plays an important role in learning and memory and an extensive body of literature is concerned with its role particularly in working memory (WM). In general, the term WM is strongly associated with its original definition by Baddeley and Hitch (1974), who famously proposed that systems for sensory storage (phonological loop, visuospatial sketchpad, and more recently, an episodic buffer) are governed by a central executive (Baddeley, 1992, 2000). The gist of this definition is that an interconnected neural system allows the brief storage of information and, importantly, its manipulation.

In primates, a seminal contribution to the understanding of this system was the discovery of Fuster and Alexander (1971) of "delay cells" in the PFC. These neurons show increased activity during the delay period of WM tasks maintaining the memory of a stimulus. Consequently, in primates including humans, WM is often modeled as "active memory" (Zipser etal., 1993; Durstewitz, 2009), a system that holds information in memory by sustaining neural activity for a few critical seconds.

Research in rodents commonly uses a broader definition of WM, that refers to "a collection of processes that include the temporary storage of information, as well as executive functions that mediate the manipulation and retrieval of trial-unique information to guide action after both short (seconds) and longer (minutes to hours) delays" (Phillips etal., 2004; see also: Mizumori et al., 1987; Floresco and Phillips, 2001). Importantly, this definition includes a much larger range of delays (seconds to many hours) compared to what is typically used in humans and non-human primates (seconds). Consequently, in rodents, the definition of WM does not necessarily refer to active memory maintenance by delay cells but might rely on different mechanisms that could be classified as learning mechanisms in primates. Thus, it is important to pay attention to the specific paradigms and definitions used when comparing results across species.

The definition of WM typically used in avian research was developed in parallel to the definition in humans (Honig, 1978). Both concepts are largely comparable with the exception that no phonological loop is conceptualized in birds. The delay durations in avian research are largely comparable to those in the primate literature and active information maintenance by delay activity is generally assumed to be the key mechanism of WM (Miller etal., 1996; Güntürkün, 2005a).

Taken together, there are fundamental terminological differences between species and it is important to keep these in mind when comparing results across species. In particular, the vast differences in delay duration used in different paradigms could potentially engage distinct neural mechanisms - what is called WM in one species might be viewed as a learning mechanism in another.

enzymes, tyrosine hydroxylase (TH), aromatic amino acid decarboxylase (AADC), and dopamine-b-hydroxylase (DBH). With modern immunohistochemical techniques it has been possible to map out in detail the location of DA neurons and their specific projections. DA neurons originate in several neighboring midbrain nuclei, being the substantia nigra pars compacta (SNc; A9) and the ventral tegmental area (VTA; A10) the ones projecting to the forebrain. The total number of TH-positive cells in VTA and SNc (bilateral count) is $\sim 20.000-30.000$ in mice and $\sim 40.000-45.000$ in rats. This number increases considerably in primates, $160.000-320.000$ in monkeys and 400.000600.000 in young humans. DA neurons send afferents to many target areas, including the several regions of the frontal cortex, with the striatum being the most densely innervated target (Björklund and Dunnett, 2007; Figure 1). PFC-projecting DA neurons are intermingled in VTA and SNc both in primates and in rodents. However, the PFC in primates is much more extensively innervated by midbrain DA afferents than in rodents (Thierry et al., 1973; Lindvall et al., 1978; Swanson, 1982; Descarries et al., 1987; Lewis and Sesack, 1997; Björklund and Dunnett, 2007).

Postsynaptically, DA exerts its actions within the PFC/NCL via receptors grouped in two major families, D1-like receptors (D1 and D5 in mammals; D1A and D1B in birds) and D2-like receptors (D2, D3, and D4 in mammals and birds), but D1-like receptors are expressed to a greater extent than D2-like receptors (Lidow et al., 1991; Durstewitz et al., 1998; Seamans and Yang, 2004; de Almeida et al., 2008; Santana et al., 2009; de Almeida and Mengod, 2010). In birds, the D1-like family is extended to include an additional receptor (D1D; Callier et al., 2003; Kubikova et al., 2010). Both families are G-protein-coupled receptors that exert slow changes of activity in the cells and act as functional neuromodulators. D1like receptors show low affinity for DA, whereas D2-like receptors show higher affinity (Seamans and Yang, 2004). For the sake of clarity, we will abbreviate D1-like and D2-like receptors as D1R and $\mathrm{D} 2 \mathrm{R}$, respectively, and will point to a specific receptor subtype whenever necessary.

Interestingly, dopaminergic signaling in the PFC depends on brain maturation and the PFC is the brain structure that matures last (Gogtay and Thompson, 2010). Analyses of human postmortem brain tissue reveal that the levels of mRNA expression of the D2R and D5R subtypes in PFC are highest in neonates and infants and decrease with age, whereas the D1R subtype mRNA expression and protein levels increase with age and are highest in adulthood (Rothmond et al., 2012). By contrast, both in rats and non-human primates, densities of the D1R and D2R subtypes peak during adolescence and decrease in adulthood (Rosenberg and Lewis, 1994; Andersen et al., 2000). In songbirds, D1R and D2R subtypes in the song nuclei increase with age and peak during adolescence (Kubikova et al., 2010). The developmental patterns of related brain regions in non-songbirds are still unclear.

\section{NEUROPHYSIOLOGY OF DA NEURONS}

"Classic" DA neurons show phasic activations (short duration bursts of action potentials) following unpredicted reward coding a quantitative "prediction error" signal, namely the difference between received and predicted reward value. A reward that is better than predicted elicits an activation (positive prediction error response), a fully predicted reward draws no response, and a reward that is worse than predicted induces a decrease in activity (negative error response; Schultz et al., 1993; Schultz, 2007, 2013). These prediction error responses of DA cells have been closely related to reinforcement learning models which assign a functional role of DA in modulating cortico-striatal inputs through a reward-prediction error teaching signal (Schultz, 1997, 2002; Morris et al., 2004, 2006; Pan 


\section{Primate (human)}

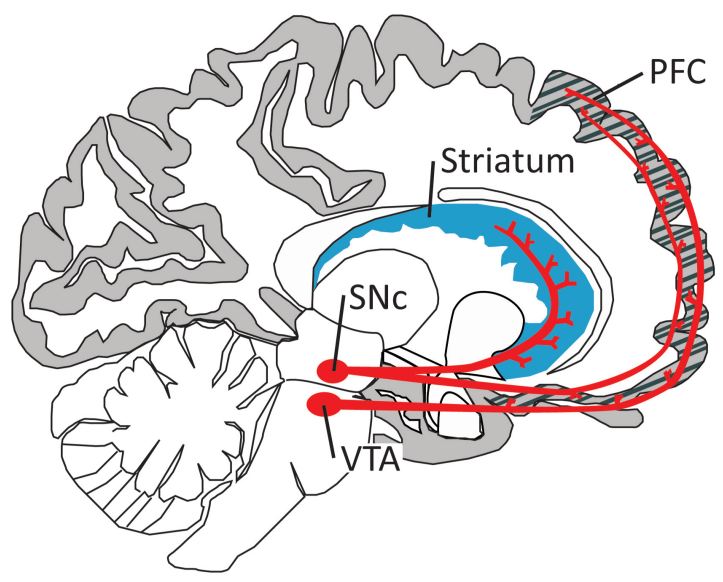

Rat

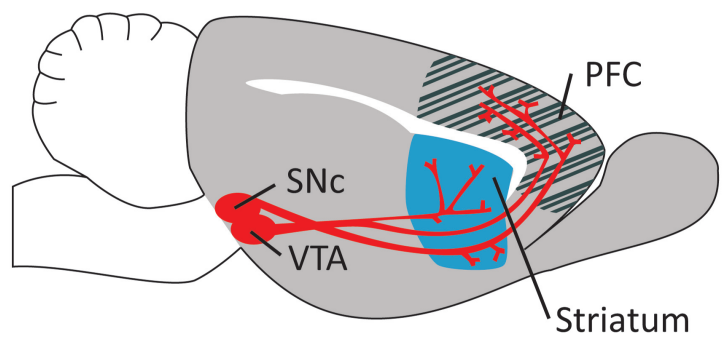

Pigeon

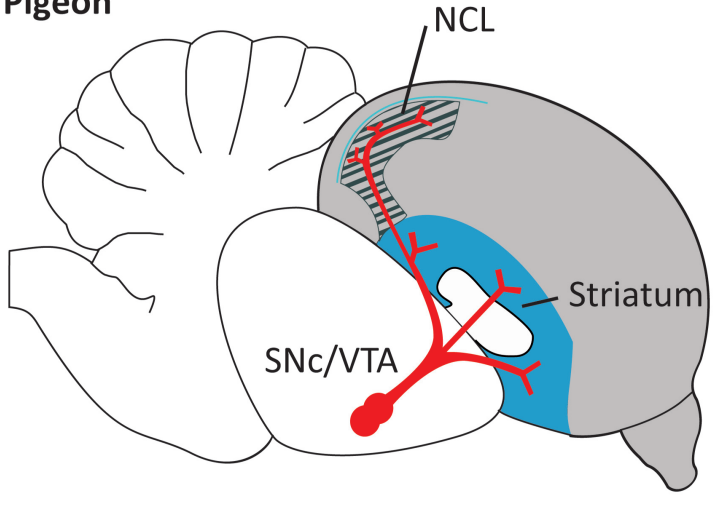

FIGURE 1 | Dopaminergic projections (in red) from the ventral tegmental area (VTA) and substantia nigra pars compacta (SNc) to the $\mathrm{PFC} / \mathrm{NCL}$ and striatum in the brain of a primate (human), a rat, and a pigeon. Pallial (cortical) areas across species are shaded in gray, the hatched area denotes the PFC/NCL, striatal areas are shaded in blue. Note that, in all species, DA neurons in both dopaminergic nuclei project to several subregions of the PFC/NCL and striatum.

et al., 2005, 2008). In fact, fast DA release consistent with these reward predicting signals of DA neurons has been measured in nucleus accumbens during associative learning (Phillips et al., 2003; Day et al., 2007). Besides "classic" reward-prediction error responses, phasic DA cell firing patterns also include responses to salient and aversive sensory stimuli (Horvitz, 2000; Joshua et al., 2008; Brischoux et al., 2009; Matsumoto and Hikosaka, 2009).

Dopamine neurons also exhibit tonic firing driven by pacemaker-like membrane currents (Grace and Bunney, 1984; Grace, 1991; Goto et al., 2007). The functional relevance of this tonic DA release is unknown. Transient suppression of tonic spiking in DA neurons follows the omission of expected reward, somehow implicating this spiking pattern in reward-based learning (Tobler et al., 2003). Recent work has shown that DA release in the striatum increases gradually (ramps up) as rats expect distant reward, perhaps providing motivational drive (Howe et al., 2013). However, these types of signals have not been described in PFC.

Which of these DA signals reaches the PFC remains currently unclear. While phasic DA prediction error signals could be used as a signal to transiently boost working memory (WM) of the corresponding stimuli (Cohen et al., 2002; O'Reilly et al., 2002), it has also been argued that mostly slower, tonic DA signals are relevant in PFC. Moreover, the phasic components of DA cell firing might be transmitted via corelease of glutamate (Seamans and Yang, 2004; Lavin etal., 2005; Castner and Williams, 2007; Sheynikhovich et al., 2013). For computational models of DA function in PFC this has two main consequences. Firstly, the timescales of tonic DA would constrain functional roles to rather general cognitive states such as arousal or attention. Secondly, DA function in PFC circuits should be carefully contrasted with known features of the putatively fast, phasic, signals of the nigrostriatal system.

In general, heterogeneity among DA cells points to additional functional aspects that are not covered by classic reinforcement learning descriptions (Berridge, 2007; Redgrave et al., 2008; Bromberg-Martin et al., 2010; Morris et al., 2010). While functional roles of VTA and SNc neurons share common properties (Ilango etal., 2014), overall evidence for different functional groups among DA cells has been emerging (Brischoux et al., 2009; Matsumoto and Hikosaka, 2009; Lammel etal., 2012; Watabe-Uchida etal., 2012). Moreover, the heterogeneity in DA cell activity patterns is probably related to heterogeneity in the anatomical pathways; DA neurons contribute to reward or aversion depending on whether they are activated from the laterodorsal tegmentum or the lateral habenula, respectively (Lammel etal., 2012). For these reasons, it has been difficult to dissociate the behavioral correlates of DA release between the projection pathways to the striatum and PFC.

\section{HUMAN STUDIES}

Investigating the direct role of DA signaling in human PFC during learning and memory brings quite a few challenges and, consequently, only few studies address this question. DA receptor agonists and antagonists cannot be injected locally, restricted to the PFC, and have to be administered systemically in humans. Our knowledge about the role of DA transmission in the human PFC, therefore, comes from studies combining imaging of the brain with other manipulations such as systemic pharmacology 
or transcranial magnetic stimulation, genetic profiling, and from work in patients with neurological and psychiatric disorders.

For instance, a recent fMRI study has revealed a connection between context dependent WM and dopaminergic signaling in human PFC (D'Ardenne etal., 2012). The authors first identified by fMRI that the dorsolateral PFC was involved in the encoding of the context. Selective disruption of activity in this region with transcranial magnetic stimulation adversely impacted performance of the participants, causally implicating PFC in context encoding. PFC activity during the task was then found to correlate with phasic responses in the VTA and SNc. Based on these results, the authors suggest that phasic DA signals regulate the encoding and updating of context representations in the PFC.

In the 1970s, it was postulated that hypofrontality (i.e., decreased blood flow in the PFC) underlies mental disorders and impaired cognitive function (Ingvar and Franzén, 1974). In the context of schizophrenia, it was proposed that an excess of DA in the mesolimbic system causes the positive symptoms via hyperstimulation of $\mathrm{D} 2 \mathrm{R}$ in the basal ganglia, whereas the cognitive and negative symptoms follow insufficient D1R activation in the frontal cortex (Abi-Dargham and Moore, 2003; Abi-Dargham, 2004). We now know that DA hypofrontality by itself cannot fully explain schizophrenia or other complex mental disorders. Impairments in PFC dopaminergic signaling and genetic profiling in these patients, however, have provided valuable information about the role of PFC DA in learning and memory. For example, schizophrenia patients exhibit imbalances in PFC dopaminergic signaling as determined by imaging approaches (Seeman, 1987; Okubo et al., 1997; Thompson et al., 2014), and show deficits in learning and WM (Kalkstein et al., 2010) that correlate with genetic variations in DA related genes (Glatt et al., 2003; Vereczkei and Mirnics, 2011). In Parkinson's disease (PD) patients, degeneration of neurons in the SNc results in decreased phasic and tonic PFC DA levels (Scatton et al., 1983; Moustafa and Gluck, 2011), which could explain the cognitive impairments present along with the motor deficits (Narayanan et al., 2013). A more direct involvement of DA in PFC-dependent memory processes was established in PD patients with and without DA medication. In a spatial WM task, subjects had to find tokens in boxes presented on a screen. Subjects that were off the DA precursor levodopa (L-DOPA) made more errors (checking boxes that had already been opened) compared to when they had received L-DOPA, indicating that DA is required for proper spatial WM performance. Surprisingly, visual learning and memory was not affected by L-DOPA in this task (Lange et al., 1992). Similarly, L-DOPA withdrawal did not affect the performance of PD patients in an N-back task, where WM is assessed when subjects are presented with a series of stimuli and have to indicate when a stimulus is the same as the one $n$ steps back (Mattay etal., 2002). However, in PD patients undergoing deep brain stimulation surgery, microstimulation of the SN disrupts reinforcement learning in a two-alternative probability learning task (Ramayya et al., 2014). Furthermore, research conducted in attention deficit hyperactivity disorder (ADHD) patients, who also display learning and memory deficits, have also provided some insight into the role of DA in learning and memory (Brown, 2006; Alderson et al., 2013). In these patients, the size of the PFC is reduced (Seidman et al., 2005), and genes involved in dopaminergic pathways are altered (Gizer et al., 2009). Taken together, the results from work in schizophrenia, $\mathrm{PD}$, and ADHD patients point to an abnormal DA transmission as being responsible for behavioral deficiencies in some learning and memory tasks that depend heavily on PFC function.

Genetic studies have also provided valuable insight into the contribution of the DA system in learning and memory. Individuals with the $\mathrm{Val} / \mathrm{Val}$ catechol-O-methyltransferase (COMT, enzyme that deactivates catecholamines) polymorphism [Val(108/158)Met] exhibit higher COMT activity that correlates with lower DA levels in the PFC (Chen et al., 2004), and have a slightly higher risk of developing schizophrenia (Sagud et al., 2010). Moreover, Val/Val carriers perform worse in the Wisconsin card sorting test (WCST) compared to carriers of the Met allele (Egan et al., 2001; Malhotra et al., 2002). The WCST consists of a battery of cognitive tasks that include WM, sensitivity to reinforcement, and behavioral flexibility. In addition, brain imaging studies indicate that Val/Val carriers need greater PFC activity to perform WM tasks (Egan et al., 2001; de Frias et al., 2010). Stress may be another factor that should be taken into consideration. Healthy human subjects under stress perform poorly in WM tasks (Olver et al., 2014) and exhibit exacerbated levels of PFC DA measured by positron emission tomography (PET; Lataster etal., 2011). In line with this finding, subjects with the above mentioned Val/Val COMT alleles and corresponding reduced levels of PFC DA perform better under stress during WM (Buckert et al., 2012).

Early evidence for the involvement of D1R in WM processes comes from work by Müller et al. (1998) that showed that systemic injections of pergolide, a combined D1R/D2R agonist, but not bromocriptine, a D2R agonist, facilitated WM performance in a delayed matching task with delays of 2-16 s. These results implicated D1R and not D2R in WM modulation. The important role of $\mathrm{D} 1 \mathrm{R}$ on WM is also suggested by the correlation between the decrease of D1R binding in the lateral PFC and the decrease in WM performance with age (Bäckman et al., 2011). However, in another study, bromocriptine was shown to improve spatial WM while the D2R antagonist haloperidol (a typical antipsychotic drug) impaired it (Luciana and Collins, 1997). Other experiments, though, did not report a general effect of bromocriptine on spatial memory (Kimberg et al., 1997; Müller et al., 1998) nor binding of the D2R agonist [11C]FLB457 correlated with performance on the WCST (Takahashi et al., 2008).

Positron emission tomography studies in humans with the radioactively marked D1R agonist [11C]SCH23390 have revealed an inverted-U relationship between D1R binding in the PFC and performance on the WCST (Takahashi et al., 2008). An inverted$\mathrm{U}$ relationship means that an optimal level of D1R activation is required for best performance and, thus, levels below and above this optimum impair performance. These experiments were meant to confirm results provided by experimentation in monkeys (see below). Further support for an inverted-U relationship between D1R density and WM comes from patients with schizophrenia. 
Deficits in WM have been associated with both decreased and increased densities of PFC D1R in these patients (Okubo et al., 1997; Abi-Dargham and Moore, 2003). Taken together, receptor studies in humans point to an important role of PFC D1R in WM with an optimal level of activation needed for best performance. By contrast, the involvement of D2R needs further elucidation.

\section{NON-HUMAN PRIMATE STUDIES}

The use of invasive approaches in monkeys has provided valuable insights into the crucial role of PFC DA and its receptors in several higher-order executive functions. In fact, global 6hydroxydopamine (6-OHDA) induced depletions of DA in the lateral PFC of monkeys allowed to establish early on the critical role of DA in WM (Brozoski etal., 1979). Later, a series of studies showed that there is an increase of extracellular DA in the PFC during WM tasks (Watanabe et al., 1997) that exerts its actions via local D1R (Sawaguchi and Goldman-Rakic, 1991, 1994; Williams and Goldman-Rakic, 1995; Murphy etal., 1996; Collins et al., 1998; Robbins, 2000; Seamans and Yang, 2004; Castner and Williams, 2007; Arnsten et al., 2010). More specifically, local injections of D1R antagonists, but not D2R antagonists, into the lateral PFC of monkeys caused deficits in oculomotor delayed-response tasks; monkeys were less accurate in making memory-guided saccades to remembered locations on the screen. We note that the WM component of the task in these studies was in the order of 1.5 to $6 \mathrm{~s}$, comparable to the human literature. More recent work has evidenced that an optimal level of $\mathrm{D} 1 \mathrm{R}$ tone is required for adequate WM performance, and this may be particularly vulnerable to changes in arousal state such as fatigue or stress (Arnsten et al., 2010; Arnsten, 2011). Thus, either too much (under stress) or too little (during fatigue) D1R stimulation impairs performance following an inverted-U shaped curve (Arnsten et al., 1994, 2010; Cai and Arnsten, 1997; Arnsten and Goldman-Rakic, 1998; Goldman-Rakic et al., 2000; Williams and Castner, 2006; Vijayraghavan et al., 2007; Arnsten, 2012). These reports in monkeys agree well with both the deleterious effects of stress on WM performance and the inverted-U relationship between D1R binding and cognitive capabilities reported in human subjects. This inverted-U modulation of D1R also occurs at the level of single PFC neurons engaged in WM. A D1R agonist modulates persistent activity during memory delays following an inverted-U response, whereby low levels of D1R stimulation enhance spatial tuning whereas high levels reduce it (Vijayraghavan et al., 2007). By contrast, D2R have little effect on delay activity and instead modulate the motor component of the task, suggesting some contribution of PFC D2R to motor control function (Wang et al., 2004). Systemic injections of D1R agonists and antagonists also alter the performance of monkeys during WM tasks, but these studies have been reviewed elsewhere (Castner and Williams, 2007).

One general question is why detrimental effects of the "wrong" DA concentration are present in the system in the first place. In other words, what could be functional reasons for decreasing WM performance? Speculatively, these could occur in situations in which the contribution of PFC to behavior is reduced anyway. For example, in high stress, fight or flight mode, behavioral control could be directed to subcortical areas to emphasize speed (Arnsten, 2012; Avery et al., 2013). Alternatively, the fine-tuning of DA concentration could be used to control the "randomness" of behavior to emphasize exploitation or exploration of certain behaviors (Sutton, 1998; Doya, 2002; Parush et al., 2011; Humphries et al., 2012). Specifically, D1R activation might push the PFC toward an exploitation mode by protecting the WM content against distractors (Durstewitz and Seamans, 2002, 2008). In contrast, based on both computational and experimental approaches, D2R activation has been proposed to support behavioral flexibility (exploration; Floresco and Magyar, 2006; Durstewitz and Seamans, 2008; Puig and Miller, 2014). As in physiological situations selective stimulation of D1R or D2R seems problematic, differences in receptor affinities may produce D2R dominated states (very low and very high DA) and D1R dominated states (intermediate DA). While these properties are also well-suited to support the on- and offset of WM-related persistent activity (Box 2), it remains unclear whether the timescales of DA modulation of the PFC firing are fast enough (Cohen et al., 2002; O'Reilly et al., 2002; Seamans and Yang, 2004; Lavin et al., 2005; Sheynikhovich et al., 2013).

The monkey lateral PFC has also been implicated in associative stimulus-response learning (Asaad etal., 1998; Pasupathy and Miller, 2005; Histed et al., 2009; Antzoulatos and Miller, 2011; Puig and Miller, 2012, 2014). Reward-prediction error responses of DA cells might be critically involved in these learning processes (Schultz, 1998, 2007, 2013; see above). Consistent with this role in reward prediction, phasic DA release occurs in nucleus accumbens that is dynamically modified by associative learning (Phillips et al., 2003; Day et al., 2007). Thus, it is plausible that these DA signals also play a role in modulating PFC-dependent learning. Indeed, Puig and Miller $(2012,2014)$ have recently shown that PFC D1R and D2R contribute to stimulus-response learning. Monkeys performed an oculomotor delayed response task where they learned by trial and error associations between visual cues and saccades to a right or left target (Figure 2A). Local microinjections of both D1R and D2R antagonists (SCH23390 and eticlopride, respectively) impaired the learning performance of the monkeys, who made more errors and needed more correct trials to learn the associations. The learning impairments correlated with a decrease of neural information about the associations in single prefrontal neurons during both the cue and memory delay $(1 \mathrm{~s})$ epochs of the trial. Noteworthy, blocking D1R impaired learning more than blocking D2R, whereas blocking D2R led to more perseverative errors (Figures 2B,C). This suggests that PFC D1R contribute to learning more than D2R, whereas the latter are more involved in cognitive flexibility. These complementary roles of D1R and D2R in PFC function agree well with the computational models mentioned earlier that propose that D1R activation helps stabilize new representations once an effective strategy has been identified (exploitation) whereas D2R activation destabilizes PFC network states favoring the exploration of new strategies (i.e., flexible processing; Durstewitz et al., 2000a; Seamans and Yang, 2004; Floresco and Magyar, 2006; Durstewitz and Seamans, 2008).

Contrary to the prominent role of DA in WM and associative learning, PFC DA does not influence familiar associations. Blockade of D1R and D2R in the lateral PFC does not cause 


\section{BOX 2 | Computational perspectives on DA, WM, and PFC persistent activity.}

Models of DA effects in the PFC can be categorized based on their biophysical details of description and their assumed DA release patterns. Furthermore, while the neuropsychological definitions ofWM seem not always to be consistent across species (Box 1), computational studies often focus on the mechanisms underlying persistent activity during delay periods.

An influential early model of DA action in the PFC (Durstewitz etal., 2000a; see also: Durstewitz etal., 1999a), bridged the gap between DA-induced conductance changes and functional roles. In small networks of multi-compartment models of pyramidal cells and interneurons, increased DA levels changed various intrinsic ionic as well as synaptic conductances. Through a differential effect on cells in high and low activity states, these changes lead to a better separation of the network response to target and distractor patterns. In particular, the network ability to maintain a robust representation of the target pattern for more than one second was improved by increased levels of DA. This feature could be a central function of DA release in PFC, to support persistent activity related to WM.

In a similar approach, increasing the dominance of feedback inhibition in the network resulted in an inverted-U shape function of DA concentration and persistent activity, suggesting a close relation to well-known inverted-U shape relations between DA levels and behavioral performance (Seamans and Yang, 2004). Overall, the ability of DA to enhance persistent activity has been verified on different modeling levels, ranging from detailed Hodgkin-Huxley-like compartmental models (Durstewitz etal., 2000b), over extended integrate-and-fire type descriptions (Brunel and Wang, 2001), to more abstract rate models (Chadderdon and Sporns, 2006). However, it remains unclear which level of model detail is necessary to capture all relevant factors of the extremely complex cellular and synaptic effects of DA in the PFC (Seamans and Yang, 2004). It has been argued that the fundamental underlying principle of changing the signal-to-noise ratio is the strengthening of both excitatory and inhibitory transmission (Cohen etal., 2002); in some cases this is achieved through changes in ionic and synaptic conductance (Durstewitz etal., 2000a), and in others through simple changes in the gain of the neural activation function (Servan-Schreiber etal., 1990). Mechanistically, D1R and D2R have been argued to be essential for changing the dynamics of PFC networks during WM. In the state space of PFC pyramidal and interneuron firing rates, baseline and persistent WM activity form two separate attractors. The level of DA controls the distance between these attractors as well as the structure of the underlying energy landscape, and thereby also the probability of noise to cause a switch between the two regimes (Durstewitz and Seamans, 2002). Still, besides the support of persistent activity, there are other aspects of DA function in PFC that might not be captured by the same principles.

While most previous modeling studies focused on the role of prefrontal DA on WM, a recent study emphasized that DA also affects long-term plasticity in the PFC (Sheynikhovich et al., 2013). Through a multi-compartment model of a PFC neuron (modified from Durstewitz et al., 2000a) they demonstrated that DA can control both the sign and amplitude of long-term plasticity. Potential functional roles of DA-mediated long-term plasticity in PFC could lie in the learning of complex high-dimensional representation of task rules and context (Mante et al., 2013; Rigotti et al., 2013). This would also expand the functional role from WM to a more fundamental role in shaping cognitive processes. The interaction of such structural changes with the other roles of DA in changing PFC activity and oscillatory patterns during WM remains one important direction for future computational approaches. any behavioral deficit in monkeys remembering highly familiar stimulus-response associations (Puig and Miller, 2012, 2014; Figures 2A,D). This agrees with the hypothesis that DA is essential for the early stages of learning, but with extended training DA appears to play a decreasing role. So there may be a transition from goal-directed to habit-based instrumental performance likely orchestrated by the basal ganglia (Wickens et al., 2007; Graybiel, 2008).

A series of investigations carried out by the groups of AC Roberts and TW Robbins have shown in monkeys that DA depletions in another region of the PFC, the orbitofrontal cortex (OFC), disrupt conditioned reinforcement (i.e., when previously neutral stimuli in the environment become associated with reward). After DA depletions restricted to the OFC monkeys were insensitive to conditioned reinforcers and persisted responding in the absence of reward, resembling the compulsive responding of drug addicts (Walker et al., 2009). The OFC is also critical for reversal learning, the ability to switch responding to a previously non-reinforced stimulus upon learning (Robbins and Roberts, 2007; Kehagia et al., 2010). After excitotoxic lesions of the OFC monkeys were able to learn novel stimulus-reward associations, but showed marked perseverative deficits in their ability to reverse the associations (Clarke et al., 2008). Interestingly, this was sensitive to serotonin but not DA depletions (Clarke et al., 2004, 2005, 2007). In contrast, DA, but not serotonin, depletions in the caudate nucleus disrupt reversal learning, revealing striking neurochemical dissociations between the DAergic and serotonergic neuromodulatory systems in fronto-striatal circuits (Clarke et al., 2011, 2014). The role of specific DA receptors in these effects have not been explored, so this important piece of information is missing. In this regard, one study showed that systemic blockade of D2R, but not D1R, impairs reversal learning in monkeys without affecting new leaning (Lee et al., 2007). However, administration of drugs in this study was systemic, making the specific contribution of PFC D1R and $\mathrm{D} 2 \mathrm{R}$ to the reported effects unclear.

\section{RODENT STUDIES}

Separate populations of PFC pyramidal neurons with unique morphological and physiological properties have been identified in mice that express only D1R or D2R (Gee et al., 2012; Seong and Carter, 2012). This is similar to the well-established direct and indirect pathways in the basal ganglia, that express D1R and D2R, respectively (Albin etal., 1989; Alexander and Crutcher, 1990; Smith et al., 1998; Gerfen and Surmeier, 2011). In fact, a recent study has demonstrated that selective (optogenetic) activation of D1R-expressing neurons in the striatum (direct pathway) promotes reinforcement learning, whereas selective activation of D2R-expressing neurons (indirect pathway) induces transient punishment (Kravitz et al., 2012). However, the specific contribution of D1R- and D2R-expressing neurons in the PFC to learning has yet to be elucidated.

Early work in rats demonstrated, as in monkeys, that elevating or depleting DA in the PFC impaired spatial WM performance (Simon, 1981; Bubser and Schmidt, 1990; Murphy et al., 1996). In keeping with studies in monkeys, there is a phasic release of DA into the PFC during delayed response tasks, the magnitude of DA efflux being predictive of memory accuracy 
A

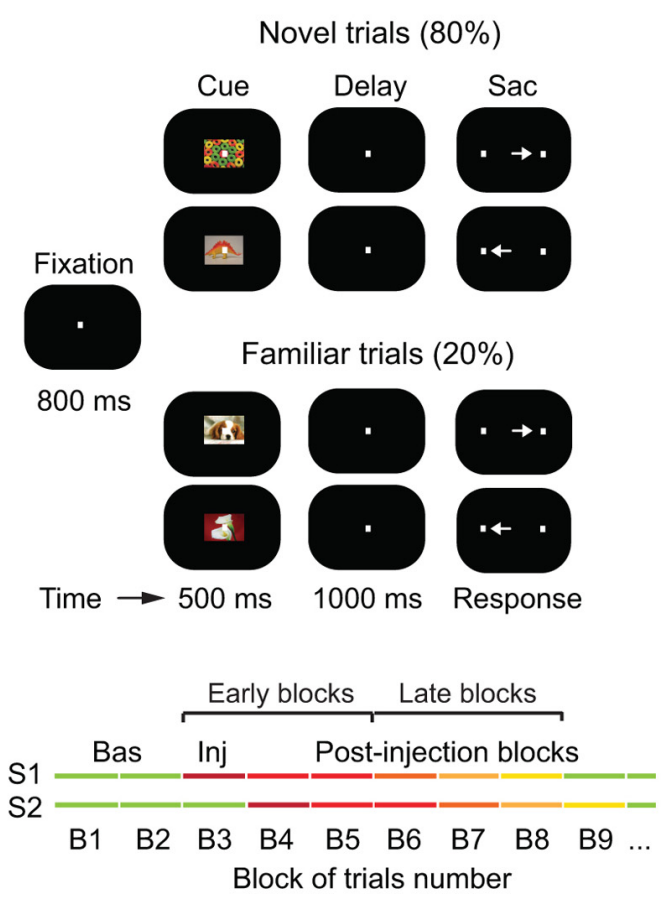

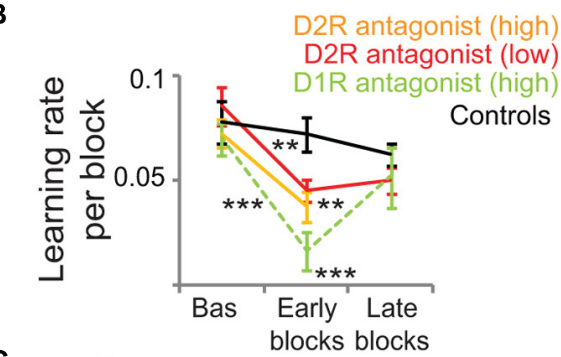

C

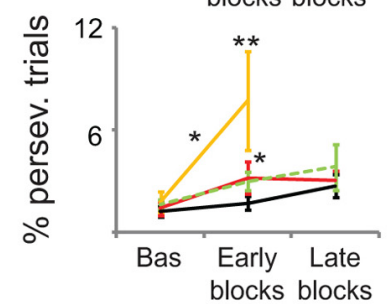

D

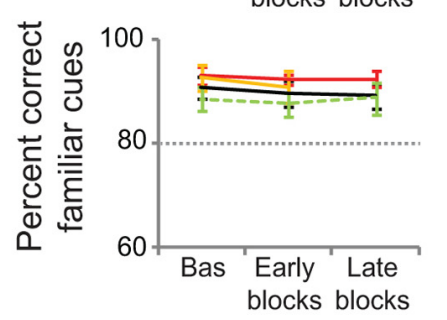

FIGURE 2 | D1R and D2R in the monkey lateral PFC modulate associative learning but not highly familiar associations. (A) Delayed associative learning and memory task. Animals fixated to start a trial. A cue object was followed by a brief memory delay and presentation of two target dots. Saccade to the target associated with the cue was rewarded with juice drops. Trials were blocked in pairs of novel cues ( $80 \%$ of trials) and pairs of familiar cues (20\% of trials). When performance on novel trials reached the learning criteria $(80 \%$ correct and 30 correct trials per novel cue), novel cues were replaced and a new block of trials started. Monkeys first completed several Baseline blocks (Bas; first green lines). Then, $3 \mu \mathrm{l}$ of either saline (controls; $n=20$ sessions), a D1R antagonist (30 $\mu \mathrm{g}$ of $\mathrm{SCH} 23390 ; n=30$ sessions), or a D2R antagonist (high concentration, $30 \mu \mathrm{g}$ of eticlopride, $n=10$ sessions; low concentration, $1 \mu \mathrm{g}$ of eticlopride, $n=26$ sessions) were pressure-injected in the left lateral PFC (Inj, injection block). Drugs were injected after different numbers of baseline blocks in different sessions (S1-S2) to account for any confounds generated by a systematic behavior of the monkeys. We classified blocks as baseline, "early" (injection block and first two postinjection blocks), or "late" (postinjection blocks 3-5). (B) Average learning rates across sessions. We measured the learning rate of each block of trials by fitting a sigmoid distribution to the performance of the monkeys on novel trials using a logistic regression model. Learning rates were the slopes of the fitted distributions. Learning rates decreased significantly after the injection of both D1R and D2R antagonists compared to baseline and post-saline blocks. The D2R antagonist reduced learning rates less than the D1R antagonist. (C) Average percent of perseverative errors (consecutive error trials of the same cue). Perseverative errors increased significantly after the injection of both D1R and D2R antagonists compared to baseline and post-saline blocks. The high concentration of the D2R antagonist elicited more perseveration than the other treatments. (D) Average percent correct of familiar trials during the baseline, early, and late blocks of trials. Dashed line depicts the $80 \%$ threshold used as part of the learning criteria. DA antagonists did not affect the performance of familiar associations. Shown are the mean and SEM. Two-way ANOVA for treatment and blocks as factors. ${ }^{*} p<0.05,{ }^{* *} p<0.01,{ }^{* *} p<0.001$, Tukey's least significant difference post hoc test. Modified from Puig and Miller (2012, 2014).
(Floresco and Phillips, 2001; Phillips et al., 2004). Moreover, these DA actions are mediated by D1R. Zahrt et al. (1997) reported that overstimulation of PFC D1R with a D1R agonist induced deleterious effects in spatial WM of rats performing a delayed alternation task, an effect reversed by pretreatment with a D1R antagonist. Rats were required to alternate between two arms to obtain a reward, with a delay between trials of 5-30 s. Another study using a comparable range of delays (0-16 s) found that intra-PFC infusions of a D1R agonist, but not a D2R antagonist, could disrupt or facilitate performance in a task designed to account for the contribution of attention to WM. Importantly, this work suggested that different levels of DA may be required for different cognitive processes (Chudasama and Robbins, 2004). Seamans and Floresco used a delayed response variant of the radial-arm maze task to demonstrate, also in rats, that other types of "WM" with comparatively longer delays (in the order of $30 \mathrm{~min}$ to several hours) are also sensitive to manipulations of PFC D1, but not D2, receptors (Seamans et al., 1998; Floresco and Phillips, 2001; Floresco and Magyar, 2006; Floresco, 2013). We note that some of these studies aimed at directly testing whether inadequate activation of PFC D1R in rodents caused the same detrimental effects on WM previously reported in monkeys, where memory delays were in the order of few seconds. Thus, and as pointed out previously (Box 1), it seems like studies across species have not reached a consensus in defining what "WM" is. However, altogether, these studies implicate PFC D1R in different types of "short-term" memory.

Also on par with primate studies, insufficient or excessive activation of PFC D1R impairs the performance of rats in WM tasks following an inverted-U shaped curve (Seamans et al., 1998; 
Mizoguchi et al., 2009; Floresco, 2013). Interestingly, this has been recently extended to a more holistic view of the role of D1R/D2R in cortico-striatal circuits. Transgenic mice with selective and reversible overexpression of $\mathrm{D} 2 \mathrm{R}$ in the striatum exhibit poor WM abilities that correlate with exacerbated PFC D1R activation (Kellendonk et al., 2006; Li et al., 2011). In contrast with the monkey literature, though, rodent work has suggested that PFC D2R could play a role in WM. Druzin et al. (2000) reported that intraPFC infusions of a D2R agonist disrupt performance of rats in a delayed-response task and that this D2R modulation of WM may be linear (i.e., lower/higher levels of D2R activation are associated with better/poorer performance). Thus, PFC D2R could also contribute to WM but following distinct principles of operation than D1R (i.e., linear vs. an inverted-U modulation; Williams and Castner, 2006; Floresco, 2013). So, perhaps the effects of the $\mathrm{D} 2 \mathrm{R}$ agonist bromocriptine observed in human studies can be attributed in part to PFC D2R.

Furthermore, D4R may be key for emotional learning. In rats, activation of $\mathrm{D} 4$, but not $\mathrm{D} 1$, receptor subtypes in the medial PFC strongly potentiates the salience of emotional associative fear memories. Furthermore, individual neurons in the medial PFC actively encode emotional learning, and this depends on D4R activation (Laviolette et al., 2005). Conversely, stimulation of D1R and not D4R blocks the recall of previously learned emotionally relevant information suggesting, again, that D1R help shape memories. So, PFC D1R and D4R may play discrete roles (memory vs. learning) in the acquisition of emotional associations (Lauzon et al., 2009).

D1R and D2R exert complex modulatory actions on the activity of PFC neurons, as shown by in vitro recordings in PFC slices of rodents (see for an extensive review Seamans and Yang, 2004). Briefly, DA tends to enhance spiking via D1R through $\mathrm{Na}^{+}, \mathrm{K}^{+}$, and $\mathrm{Ca}^{2+}$ currents (Yang and Seamans, 1996; Gorelova and Yang, 2000), an effect also observed in PFC slices of monkeys (Henze et al., 2000; González-Burgos et al., 2002). Conversely, DA decreases spiking via D2R, possibly through modulation of glutamatergic receptors and $\mathrm{Na}^{+}$conductances (Gulledge and Jaffe, 1998, 2001; Gorelova and Yang, 2000; Tseng and O'Donnell, 2004). Moreover, stimulation of PFC D2R can also induce an afterdepolarization mediated by L-type $\mathrm{Ca}^{2+}$ channels and NMDA receptors (Gee et al., 2012). Besides these contributions of DA to the modulation of PFC activity, several rodent studies have also provided evidence that PFC neurons shape the activity of DA neurons. For example, Takahashi et al. (2011) found that OFC inactivation impaired state-value representations in VTA DA cell activity, in particular the effect of the animals own action plan on the state value. Furthermore, Jo et al. (2013) showed that PFC inactivation increases the DA response to reward-predicting stimuli. This matches a series of computational modeling studies in which PFC becomes part of the system that determines the value of the current state and propagates this information to the DA system (e.g., Frank et al., 2001; O'Reilly and Frank, 2006; Hazy et al., 2007). Although this supports a general role of PFC in shaping DA cell activity, the specific contribution during behavior depends on the corresponding firing patterns of the PFC neurons that affect DA cells.

\section{BIRD STUDIES}

Higher cognitive abilities evolved largely independently in birds and mammals. This parallel evolution gave rise to several crucial differences in neural organization. While avian and mammalian striatum and pallium are homolog (derived from a common ancestor), there are considerable differences in the organization of the pallium (Jarvis et al., 2005). For instance, the avian telencephalon does not have a pallial commissure comparable to the mammalian corpus callosum. The most notable difference, however, is the lack of the typical cortical lamination in the avian pallium (Jarvis et al., 2005). In other words, in spite of a shared evolutionary ancestry and a similar functionality, the avian and mammalian "cortex" look entirely different: what has evolved into layers in the mammalian brain might have evolved into different regions in the avian brain (Jarvis et al., 2013). Other organizational principles were preserved or independently evolved. For instance, a recent analysis of the avian connectome revealed a very similar network organization between birds and mammals (Shanahan et al., 2013). Using graph theory, the authors found that the telencephalon of both species has a comparable organization into modular, smallworld networks with a connective core of hub nodes. The most relevant here is the "prefrontal" hub. While the avian brain has no homolog of the mammalian PFC, it has a functional analog (structure with comparable functionality) - the NCL. A detailed comparison between both structures has been provided elsewhere (Güntürkün, 2005a,b; Kirsch et al., 2008). Briefly, PFC and NCL are centers of multimodal integration that are closely connected to all secondary sensory and motor regions (Kröner and Güntürkün, 1999).

Much like the PFC, the NCL is involved in WM as revealed by lesion studies (Mogensen and Divac, 1982; Güntürkün, 1997) and single cell recordings in pigeons during Go/Nogo tasks (Diekamp et al., 2002). Recently, an elegant study demonstrated that single neurons in the NCL of crows maintain memory information in two versions of a delayed match to sample task (DMS; Veit et al., 2014), the classical paradigm of WM research in primates. The animals were trained to view a sample image and indicate this image among similar images following a short delay (1-2.3 s). Similar experiments revealed an involvement of NCL in other cognitive functions such as categorization (Kirsch etal., 2009), the integration of time-to-reward with reward amount (Kalenscher et al., 2005), and executive control over what information is maintained in WM (Rose and Colombo, 2005). Another hallmark of prefrontal function, the processing of rules that guide behavior, was recently reported in the NCL of crows (Veit and Nieder, 2013). The authors used the same paradigm that was used in the original demonstration of such processes in primate PFC, a modified DMS task (Wallis et al., 2001). They report that single neurons in the NCL represent behavioral rules that instruct the animals how to respond to subsequent stimuli, a result that mirrors the original findings in the PFC.

The NCL, as the PFC, is the prime cortical (pallial) target of dopaminergic innervation (Durstewitz etal., 1999b). As in mammals, these projections arise in VTA and SNc (Waldmann and Güntürkün, 1993; Figure 1). Dopaminergic projections to the avian telencephalon show two distinct anatomical features 
(Wynne and Güntürkün, 1995). One type, "en passant” projections, are also found in the mammalian brain. These axons travel through the telencephalon, contacting a large number of dendrites and somata of predominantly smaller target neurons. The other type, "baskets," has not been reported in the mammalian brain. Here, individual fibers densely wrap around the somata and initial dendrites of predominantly larger cells. Interestingly, this type of innervation might be functionally comparable to the pattern of innervation in the mammalian cortex. In mammals, large pyramidal neurons lie mainly in deeper layers and are targeted by DA terminals through their proximal (in primates also distal) dendrites. The basket structures might be a way to generate a similar innervation of larger cells in the absence of cortical organization (Durstewitz et al., 1999b). Compared to the mammalian PFC, the avian NCL contains members of both DA receptor families, with a considerably lower density of D2 compared to D1 receptors (Dietl and Palacios, 1988; Durstewitz et al., 1998).

Overall, the role of DA in the avian brain is largely comparable to its role in the mammalian brain. DA is involved in motor control and learning, and in birds it also contributes to the acquisition and control of birdsong (Rieke, 1980, 1981; Güntürkün, 2005a; Fee and Goldberg, 2011). Even though birdsong is a major focus of avian research, here we will only briefly refer to this work. It has been reviewed extensively elsewhere and the main focus of the song literature is the role of DA in basal ganglia circuits (Kubikova et al., 2010; Fee and Goldberg, 2011; Simonyan et al., 2012). To our knowledge, no study has recorded avian dopaminergic neurons during learning, so there is no direct evidence for reward prediction error coding in avian DA neurons. However, several studies provide indirect evidence for temporal discounting (TD)-learning in birds. The only study that recorded from single DA neurons in the VTA of songbirds showed that DA neurons are strongly modulated by social context. The authors interpret this result in the light of "approval" - positive feedback of the females that the male subjects sang to (Yanagihara and Hessler, 2006). Later work confirmed that such social context activity is involved in modulating the singing-related activation of the song system (Hara et al., 2007). Further evidence comes from behavioral studies. Pigeons learn a simple discrimination task faster if they receive a larger reward for correct discrimination than with a smaller contingent reward. This difference in learning rate can be predicted by different reward prediction errors due to the different reward magnitudes (Rose et al., 2009b). Furthermore, injections of D1R antagonists in the striatum abolish this effect (Rose et al., 2013). Interestingly, the birds are still able to learn the discrimination but the learning rate is no longer modulated by the contingent reward magnitude. Learning shows an average rate with a slight decrease in performance on a large reward and a slight increase in performance with a small reward.

As in the mammalian PFC, DA in the avian NCL is critically involved in mechanisms of learning and memory. DA levels in the PFC of monkeys increase during WM tasks (Watanabe et al., 1997) and, consistently, microdialysis in the NCL of pigeons show an increase in DA during a DMS task with a delay (4 s) compared to the same task without a delay (Karakuyu et al., 2007).
Furthermore, injections of a D1R agonist (SKF81297) into the NCL and striatum improve performance on a DMS task (Herold et al., 2008). Interestingly, these injections were only beneficial on days with low performance; if the animals performed well, agonist injections disrupted performance. These findings are in line with the mammalian literature showing that DA modulates performance following an inverted-U shaped curve, where too much or too little D1R activation is detrimental to performance. It also complements nicely the reports showing that humans with genetically lower levels of DA in PFC are less susceptible to the detrimental effects of stress on WM (see Human Studies). In addition, and again in line with the mammalian literature on WM, injections of a D1R antagonist (SCH23390) into the NCL disrupt the ability of pigeons to focus their attention over longer periods of time and to ignore distracting stimuli (Rose et al., 2010).

In a recent study, Herold et al. (2012) assessed the expression of different DA receptor types in the NCL of pigeons trained on different cognitive tasks. This approach allowed the dissociation of changes in receptor expression due to WM (using a DMS task), stimulus selection (a stimulus-response task), or general task components such as reward and response selection. It is noteworthy that the mammalian D1R family is extended in the avian brain. In addition to $\mathrm{D} 1 \mathrm{~A}(\mathrm{D} 1)$ and $\mathrm{D} 1 \mathrm{~B}(\mathrm{D} 5)$ receptors, the avian brain also contains the receptor $\mathrm{D} 1 \mathrm{D}$. The authors report that general task components have no influence on D1R expression in the NCL. However, WM components increase expression of D1B and stimulus-response learning increases expression of D1A and D1D receptors. None of the task components affected the expression of D2R. These results demonstrate an involvement of DA receptors in the NCL not only in WM but also in learning mechanisms (Herold et al., 2012). In line with these results, microinjections of a D1R antagonist (SCH23390) to the NCL of pigeons resulted in severe disruptions of discrimination reversal learning (Diekamp et al., 2000). This result is in contrast to the finding that DA in caudate nucleus, but not the OFC, of monkeys is required for reversal learning (see Non-Human Primate Studies; Clarke et al., 2004, 2005, 2007, 2011).

\section{CONCLUSION}

Despite decades of intense research, we are only now starting to comprehend the specific roles of DA in several PFC-dependent learning and memory processes. A main obstacle in understanding the complex DA modulation of PFC function, both at anatomical and physiological levels, is the outstanding heterogeneity and specificity of the DA system itself. Therefore, a cross-species comparison may contribute to identify general principles of DA function in the PFC. Each model species discussed here provides its unique advantages and challenges. Certainly, one of the main goals of studying the dopaminergic system is to expand our understanding of the healthy and diseased human brain in order to develop better treatments for neurological and psychiatric disorders with abnormal DA transmission. Since this research poses many technical constraints, non-human primates offer an alternative to study complex behavior and higher cognitive functions. In contrast, rodents can be manipulated vastly with a variety of genetic/optogenetic approaches, but their cognitive abilities 
might not be sufficient to address higher cognitive functions of humans. Finally, studying the avian brain offers an evolutionary perspective that might help identify crucial features and constraints of the dopaminergic system. Indeed, the crucial role of DA in executive function is highlighted by the fact that the independent evolution of higher-order cognition in birds gave rise to a largely comparable DA function - even in the absence of cortical layering.

Some major findings have been consistently replicated in different species, establishing their robustness. First, elevating or depleting DA levels in PFC impair performance in WM tasks. Second, PFC DA modulates WM via D1R. The potential involvement of D2R in WM is more controversial. Third, PFC D1R modulate WM following an inverted-U shaped curve. That is, an optimal level of D1R activation is required for adequate WM performance, and this is sensitive to changes in arousal state such as fatigue or stress. Recent studies in monkeys point to interesting extensions of these findings, but still need to be confirmed in other species and in other paradigms. They showed that the inverted- $U$ curve modulation of WM may also occur at the level of spiking in PFC neurons, and that both PFC D1R and $\mathrm{D} 2 \mathrm{R}$ play relevant roles in associative learning but not associative memory.

Clearly, more work will be necessary to fully understand the role of different receptor subtypes present in the avian and mammalian brains in learning and memory processes. In order to succeed, and as underscored in this review, researchers working on different disciplines and with different species will need to reach a consensus in how to define different types of learning and memory processes, paying particular attention to WM-related concepts and terminology (Box 1). Computational modeling could provide such unified definitions and hypotheses that are testable across species.

Importantly, recent investigations conducted in rodents have highlighted the close interaction between D1 and D2 receptors present in cortico-striatal circuits. In addition, separate populations of pyramidal neurons have been identified in the rat PFC that preferentially express only D1R or D2R, similarly to the D1Rexpressing direct and D2R-expressing indirect pathways of the basal ganglia. Although the specific contribution of these PFC neuron populations to learning and memory has yet to be elucidated, the use of genetic and invasive approaches in rodents is proving to be an excellent source of information. However, nonhuman primate models are better suited to gain deeper insights into the role of DA in more sophisticated tasks that are closer to the human cognitive repertoire. Unfortunately, genetic manipulations and invasive approaches such as optogenetics are just beginning to be developed in primates. A rapid advancement in the development of techniques applicable to humans is especially necessary, since human studies on the role DA in learning and memory have been particularly scarce. In this regard, it is now possible to measure DA release with accurate timescales by molecular fMRI (Lee et al., 2014). We hope that these emerging technical advances in primates will allow a more detailed understanding of the roles of D1R and D2R in higher-order executive function. This will be particularly important for the development of adequate drug therapies for patients with disorders that show disrupted prefrontal DA signaling such as schizophrenia, PD, and ADHD.

\section{ACKNOWLEDGMENTS}

This work was supported by the BrainLinks-BrainTools Cluster of Excellence funded by the German Research Foundation (DFG, grant no. EXC 1086, to Robert Schmidt) and the Volkswagen Foundation (Freigeist fellowship to Jonas Rose). We also acknowledge support from the Deutsche Forschungsgemeinschaft and Open Access Publishing Fund of Tuebingen University (to Jonas Rose and Nadja Freund).

\section{REFERENCES}

Abi-Dargham, A. (2004). Do we still believe in the dopamine hypothesis? New data bring new evidence. Int. J. Neuropsychopharmacol. 7(Suppl. 1), S1-S5. doi: $10.1017 /$ S1461145704004110

Abi-Dargham, A., and Moore, H. (2003). Prefrontal DA transmission at D1 receptors and the pathology of schizophrenia. Neuroscientist 9, 404-416. doi: $10.1177 / 1073858403252674$

Albin, R. L., Young, A. B., and Penney, J. B. (1989). The functional anatomy of basal ganglia disorders. Trends Neurosci. 12, 366-375. doi: 10.1016/01662236(89)90074-X

Alderson, R. M., Kasper, L. J., Hudec, K. L., and Patros, C. H. G. (2013). Attentiondeficit/hyperactivity disorder (ADHD) and working memory in adults: a metaanalytic review. Neuropsychology 27, 287-302. doi: 10.1037/a0032371

Alexander, G. E., and Crutcher, M. D. (1990). Functional architecture of basal ganglia circuits: neural substrates of parallel processing. Trends Neurosci. 13, 266-271. doi: 10.1016/0166-2236(90)90107-L

Andersen, S. L., Thompson, A. T., Rutstein, M., Hostetter, J. C., and Teicher, M. H. (2000). Dopamine receptor pruning in prefrontal cortex during the periadolescent period in rats. Synapse 37, 167-169. doi: 10.1002/10982396(200008)37:2<167::AID-SYN11>3.0.CO;2-B

Antzoulatos, E. G., and Miller, E. K. (2011). Differences between neural activity in prefrontal cortex and striatum during learning of novel abstract categories. Neuron 71, 243-249. doi: 10.1016/j.neuron.2011.05.040

Arnsten, A. F. (2012). Neuromodulation of thought: flexibilities and vulnerabilities in prefrontal cortical network synapses. Neuron 76, 223-239. doi: 10.1016/j.neuron.2012.08.038

Arnsten, A. F., Cai, J. X., Murphy, B. L., and Goldman-Rakic, P. S. (1994). Dopamine D1 receptor mechanisms in the cognitive performance of young adult and aged monkeys. Psychopharmacology (Berl.) 116, 143-151. doi: 10.1007/BF02245056

Arnsten, A. F., and Goldman-Rakic, P. S. (1998). Noise stress impairs prefrontal cortical cognitive function in monkeys: evidence for a hyperdopaminergic mechanism. Arch. Gen. Psychiatry 55, 362-368. doi: 10.1001/archpsyc.55. 4.362

Arnsten, A. F. T. (2011). Catecholamine influences on dorsolateral prefrontal cortical networks. Biol. Psychiatry 69, e89-e99. doi: 10.1016/j.biopsych.2011. 01.027

Arnsten, A. F. T., Paspalas, C. D., Gamo, N. J., Yang, Y., and Wang, M. (2010). Dynamic network connectivity: a new form of neuroplasticity. Trends Cogn. Sci. 14, 365-375. doi: 10.1016/j.tics.2010.05.003

Asaad, W. F., Rainer, G., and Miller, E. K. (1998). Neural activity in the primate prefrontal cortex during associative learning. Neuron 21, 1399-1407. doi: 10.1016/S0896-6273(00)80658-3

Avery, M. C., Dutt, N., and Krichmar, J. L. (2013). A large-scale neural network model of the influence of neuromodulatory levels on working memory and behavior. Front. Comput. Neurosci. 7:133. doi: 10.3389/fncom.2013. 00133

Bäckman, L., Karlsson, S., Fischer, H., Karlsson, P., Brehmer, Y., Rieckmann, A., etal. (2011). Dopamine D1 receptors and age differences in brain activation during working memory. Neurobiol. Aging 32, 1849-1856. doi: 10.1016/j.neurobiolaging.2009.10.018

Baddeley, A. (1992). Working memory. Science 255, 556-559. doi: 10.1126/science. 1736359

Baddeley, A. (2000). The episodic buffer: a new component of working memory? Trends Cogn. Sci. 4, 417-423. doi.org/10.1016/S1364-6613(00)01538-2 
Baddeley, A., and Hitch, G. (1974). "Working memory," in The Psychology of Learning and Motivation, ed. G. H. Bower (San Diego: Academic Press), 47-90.

Berridge, K. C. (2007). The debate over dopamine's role in reward: the case for incentive salience. Psychopharmacology (Berl.) 191, 391-431. doi: 10.1007/s00213-006-0578-x

Björklund, A., and Dunnett, S. B. (2007). Dopamine neuron systems in the brain: an update. Trends Neurosci. 30, 194-202. doi: 10.1016/j.tins.2007. 03.006

Brischoux, F., Chakraborty, S., Brierley, D. I., and Ungless, M. A. (2009). Phasic excitation of dopamine neurons in ventral VTA by noxious stimuli. Proc. Natl. Acad. Sci. U.S.A. 106, 4894-4899. doi: 10.1073/pnas.0811507106

Bromberg-Martin, E. S., Matsumoto, M., and Hikosaka, O. (2010). Dopamine in motivational control: rewarding, aversive, and alerting. Neuron 68, 815-834. doi: 10.1016/j.neuron.2010.11.022

Brown, T. E. (2006). Executive functions and attention deficit hyperactivity disorder: implications of two conflicting views. Int. J. Disabil. Dev. Educ. 53, 35-46. doi 10.1080/10349120500510024

Brozoski, T. J., Brown, R. M., Rosvold, H. E., and Goldman, P. S. (1979). Cognitive deficit caused by regional depletion of dopamine in prefrontal cortex of rhesus monkey. Science 205, 929-932. doi: 10.1126/science.112679

Brunel, N., and Wang, X. J. (2001). Effects of neuromodulation in a cortical network model of object working memory dominated by recurrent inhibition. J. Comput. Neurosci. 11, 63-85. doi: 10.1023/A:1011204814320

Bubser, M., and Schmidt, W. J. (1990). 6-Hydroxydopamine lesion of the rat prefrontal cortex increases locomotor activity, impairs acquisition of delayed alternation tasks, but does not affect uninterrupted tasks in the radial maze. Behav. Brain Res. 37, 157-168. doi: 10.1016/0166-4328(90)90091-R

Buckert, M., Kudielka, B. M., Reuter, M., and Fiebach, C. J. (2012). The COMT Val158Met polymorphism modulates working memory performance under acute stress. Psychoneuroendocrinology 37, 1810-1821. doi: 10.1016/j.psyneuen.2012.03.014

Cai, J. X., and Arnsten, A. F. (1997). Dose-dependent effects of the dopamine D1 receptor agonists A77636 or SKF81297 on spatial working memory in aged monkeys. J. Pharmacol. Exp. Ther. 283, 183-189.

Callier, S., Snapyan, M., Le Crom, S., Prou, D., Vincent, J.-D., and Vernier, P. (2003). Evolution and cell biology of dopamine receptors in vertebrates. Biol. Cell 95, 489-502. doi: 10.1016/S0248-4900(03)00089-3

Castner, S. A., and Williams, G. V. (2007). Tuning the engine of cognition: a focus on NMDA/D1 receptor interactions in prefrontal cortex. Brain Cogn. 63, 94-122. doi: 10.1016/j.bandc.2006.11.002

Chadderdon, G. L., and Sporns, O. (2006). A large-scale neurocomputational model of task-oriented behavior selection and working memory in prefrontal cortex. $J$. Cogn. Neurosci. 18, 242-257. doi: 10.1162/jocn.2006.18.2.242

Chen, J., Lipska, B. K., Halim, N., Ma, Q. D., Matsumoto, M., Melhem, S., et al. (2004). Functional analysis of genetic variation in catechol-O-Methyltransferase (COMT): effects on mRNA, protein, and enzyme activity in postmortem human brain. Am. J. Hum. Genet. 75, 807-821. doi: 10.1086/425589

Chudasama, Y., and Robbins, T. W. (2004). Dopaminergic modulation of visual attention and working memory in the rodent prefrontal cortex. Neuropsychopharmacology 29, 1628-1636. doi: 10.1038/sj.npp. 1300490

Clarke, H. F., Cardinal, R. N., Rygula, R., Hong, Y. T., Fryer, T. D., Sawiak, S. J., et al. (2014). Orbitofrontal dopamine depletion upregulates caudate dopamine and alters behavior via changes in reinforcement sensitivity. J. Neurosci. 34, 76637676. doi: 10.1523/JNEUROSCI.0718-14.2014

Clarke, H. F., Dalley, J. W., Crofts, H. S., Robbins, T. W., and Roberts, A. C. (2004). Cognitive inflexibility after prefrontal serotonin depletion. Science 304, 878-880. doi: $10.1126 /$ science. 1094987

Clarke, H. F., Hill, G. J., Robbins, T. W., and Roberts, A. C. (2011). Dopamine, but not serotonin, regulates reversal learning in the marmoset caudate nucleus. $J$. Neurosci. 31, 4290-4297. doi: 10.1523/JNEUROSCI.5066-10.2011

Clarke, H. F., Robbins, T. W., and Roberts, A. C. (2008). Lesions of the medial striatum in monkeys produce perseverative impairments during reversal learning similar to those produced by lesions of the orbitofrontal cortex. J. Neurosci. 28 , 10972-10982. doi: 10.1523/JNEUROSCI.1521-08.2008

Clarke, H. F., Walker, S. C., Crofts, H. S., Dalley, J. W., Robbins, T. W., and Roberts, A. C. (2005). Prefrontal serotonin depletion affects reversal learning but not attentional set shifting. J. Neurosci. 25, 532-538. doi: 10.1523/JNEUROSCI.369004.2005
Clarke, H. F., Walker, S. C., Dalley, J. W., Robbins, T. W., and Roberts, A. C. (2007), Cognitive inflexibility after prefrontal serotonin depletion is behaviorally and neurochemically specific. Cereb. Cortex 17, 18-27. doi: 10.1093/cercor/bhj120

Cohen, J. D., Braver, T. S., and Brown, J. W. (2002). Computational perspectives on dopamine function in prefrontal cortex. Curr. Opin. Neurobiol. 12, 223-229. doi: 10.1016/S0959-4388(02)00314-8

Collins, P., Roberts, A. C., Dias, R., Everitt, B. J., and Robbins, T. W. (1998). Perseveration and strategy in a novel spatial self-ordered sequencing task for nonhuman primates: effects of excitotoxic lesions and dopamine depletions of the prefrontal cortex. J. Cogn. Neurosci. 10, 332-354. doi: 10.1162/08989299 8562771

Colombo, M., and Broadbent, N. (2000). Is the avian hippocampus a functional homologue of the mammalian hippocampus? Neurosci. Biobehav. Rev. 24, 465484. doi: 10.1016/S0149-7634(00)00016-6

D’Ardenne, K., Eshel, N., Luka, J., Lenartowicz, A., Nystrom, L. E., and Cohen, J. D. (2012). Role of prefrontal cortex and the midbrain dopamine system in working memory updating. Proc. Natl. Acad. Sci. U.S.A. 109, 19900-19909. doi: 10.1073/pnas.1116727109

Day, J. J., Roitman, M. F., Wightman, R. M., and Carelli, R. M. (2007). Associative learning mediates dynamic shifts in dopamine signaling in the nucleus accumbens. Nat. Neurosci. 10, 1020-1028. doi: 10.1038/nn1923

de Almeida, J., and Mengod, G. (2010). D2 and D4 dopamine receptor mRNA distribution in pyramidal neurons and GABAergic subpopulations in monkey prefrontal cortex: implications for schizophrenia treatment. Neuroscience 170, 1133-1139. doi: 10.1016/j.neuroscience.2010.08.025

de Almeida, J., Palacios, J. M., and Mengod, G. (2008). "Distribution of 5-HT and DA receptors in primate prefrontal cortex: implications for pathophysiology and treatment," in Progress in Brain Research, Vol. 172, Serotonin-Dopamine Interaction: Experimental Evidence and Therapeutic Relevance, eds G. D. Giovanni, V. D. Matteo, and E. Esposito (Oxford: Elsevier LTD), 101-115.

de Frias, C. M., Marklund, P., Eriksson, E., Larsson, A., Oman, L., Annerbrink, K., et al. (2010). Influence of COMT gene polymorphism on fMRI-assessed sustained and transient activity during a working memory task. J. Cogn. Neurosci. 22, 1614-1622. doi: 10.1162/jocn.2009.21318

Descarries, L., Lemay, B., Doucet, G., and Berger, B. (1987). Regional and laminar density of the dopamine innervation in adult rat cerebral cortex. Neuroscience 21, 807-824. doi: 10.1016/0306-4522(87)90038-8

Diekamp, B., Kalt, T., and Güntürkün, O. (2002). Working memory neurons in pigeons. J. Neurosci. 22, RC210.

Diekamp, B., Kalt, T., Ruhm, A., Koch, M., and Güntürkün, O. (2000). Impairment in a discrimination reversal task after D1 receptor blockade in the pigeon "prefrontal cortex". Behav. Neurosci. 114, 1145-1155. doi: 10.1037/07357044.114.6.1145

Dietl, M. M., and Palacios, J. M. (1988). Neurotransmitter receptors in the avian brain. I. Dopamine receptors. Brain Res. 439, 354-359. doi: 10.1016/00068993(88)91494-1

Doya, K. (2002). Metalearning and neuromodulation. Neural Netw. 15, 495-506. doi: 10.1016/S0893-6080(02)00044-8

Druzin, M. Y., Kurzina, N. P., Malinina, E. P., and Kozlov, A. P. (2000). The effects of local application of D2 selective dopaminergic drugs into the medial prefrontal cortex of rats in a delayed spatial choice task. Behav. Brain Res. 109, 99-111. doi: 10.1016/S0166-4328(99)00166-7

Durstewitz, D. (2009). Implications of synaptic biophysics for recurrent network dynamics and active memory. Neural Netw. 22, 1189-1200. doi: 10.1016/j.neunet.2009.07.016

Durstewitz, D., Kelc, M., and Güntürkün, O. (1999a). A neurocomputational theory of the dopaminergic modulation of working memory functions. J. Neurosci. 19, 2807-2822.

Durstewitz, D., Kröner, S., and Güntürkün, O. (1999b). The dopaminergic innervation of the avian telencephalon. Prog. Neurobiol. 59, 161-195. doi: 10.1016/S0301-0082(98)00100-2

Durstewitz, D., Kröner, S., Hemmings, H. C., and Güntürkün, O. (1998). The dopaminergic innervation of the pigeon telencephalon: distribution of DARPP32 and co-occurrence with glutamate decarboxylase and tyrosine hydroxylase. Neuroscience 83, 763-779. doi: 10.1016/S0306-4522(97)00450-8

Durstewitz, D., and Seamans, J. K. (2002). The computational role of dopamine D1 receptors in working memory. Neural Netw. 15, 561-572. doi: 10.1016/S0893$6080(02) 00049-7$ 
Durstewitz, D., and Seamans, J. K. (2008). The dual-state theory of prefrontal cortex dopamine function with relevance to catechol-Omethyltransferase genotypes and schizophrenia. Biol. Psychiatry 64, 739-749. doi: 10.1016/j.biopsych.2008.05.015

Durstewitz, D., Seamans, J. K., and Sejnowski, T. J. (2000a). Dopamine-mediated stabilization of delay-period activity in a network model of prefrontal cortex. $J$. Neurophysiol. 83, 1733-1750.

Durstewitz, D., Seamans, J. K., and Sejnowski, T. J. (2000b). Neurocomputational models of working memory. Nat. Neurosci. 3, 1184-1191. doi: 10.1038/ 81460

Egan, M. F., Goldberg, T. E., Kolachana, B. S., Callicott, J. H., Mazzanti, C. M., Straub, R. E., et al. (2001). Effect of COMT Val108/158 Met genotype on frontal lobe function and risk for schizophrenia. Proc. Natl. Acad. Sci. U.S.A. 98, 6917-6922. doi: 10.1073/pnas.111134598

Emery, N. J., and Clayton, N. S. (2004). The mentality of crows: convergent evolution of intelligence in corvids and apes. Science 306, 1903-1907. doi: $10.1126 /$ science. 1098410

Fee, M. S., and Goldberg, J. H. (2011). A hypothesis for basal ganglia-dependent reinforcement learning in the songbird. Neuroscience 198, 152-170. doi: 10.1016/j.neuroscience.2011.09.069

Floresco, S. B. (2013). Prefrontal dopamine and behavioral flexibility: shifting from an "inverted-U" towards a family of functions. Front. Neurosci. 7:62. doi: $10.3389 /$ fnins.2013.00062

Floresco, S. B., and Magyar, O. (2006). Mesocortical dopamine modulation of executive functions: beyond working memory. Psychopharmacology 188, 567585. doi: 10.1007/s00213-006-0404-5

Floresco, S. B., and Phillips, A. G. (2001). Delay-dependent modulation of memory retrieval by infusion of a dopamine D1 agonist into the rat medial prefrontal cortex. Behav. Neurosci. 115, 934-939. doi: 10.1037/0735-7044.115. 4.934

Frank, M. J., Loughry, B., and O’Reilly, R. C. (2001). Interactions between frontal cortex and basal ganglia in working memory: a computational model. Cogn. Affect. Behav. Neurosci. 1, 137-160. doi: 10.3758/CABN.1.2.137

Fuster, J. M., and Alexander, G. E. (1971). Neuron activity related to short-term memory. Science 173, 652-654. doi: 10.1126/science.173.3997.652

Gee, S., Ellwood, I., Patel, T., Luongo, F., Deisseroth, K., and Sohal, V. S. (2012). Synaptic activity unmasks dopamine D2 receptor modulation of a specific class of layer V pyramidal neurons in prefrontal cortex. J. Neurosci. 32, 4959-4971. doi: 10.1523/JNEUROSCI.5835-11.2012

Gerfen, C. R., and Surmeier, D. J. (2011). Modulation of striatal projection systems by dopamine. Annu. Rev. Neurosci. 34, 441-466. doi: 10.1146/annurev-neuro061010-113641

Gizer, I. R., Ficks, C., and Waldman, I. D. (2009). Candidate gene studies of ADHD: a meta-analytic review. Hum. Genet. 126, 51-90. doi: 10.1007/s00439-0090694-x

Glatt, S. J., Faraone, S. V., and Tsuang, M. T. (2003). Meta-analysis identifies an association between the dopamine D2 receptor gene and schizophrenia. Mol. Psychiatry 8, 911-915. doi: 10.1038/sj.mp.4001321

Gogtay, N., and Thompson, P. M. (2010). Mapping gray matter development: implications for typical development and vulnerability to psychopathology. Brain Cogn. 72, 6. doi: 10.1016/j.bandc.2009.08.009

Goldman-Rakic, P. S., Muly, I. I. I., and Williams, G. V. (2000). D1 receptors in prefrontal cells and circuits. Brain Res. Rev. 31, 295-301. doi: 10.1016/S01650173(99)00045-4

González-Burgos, G., Kröner, S., Krimer, L. S., Seamans, J. K., Urban, N. N., Henze, D. A., etal. (2002). Dopamine modulation of neuronal function in the monkey prefrontal cortex. Physiol. Behav. 77, 537-543. doi: 10.1016/S0031-9384(02)00940-X

Gorelova, N. A., and Yang, C. R. (2000). Dopamine D1/D5 receptor activation modulates a persistent sodium current in rat prefrontal cortical neurons in vitro. J. Neurophysiol. 84, 75-87.

Goto, Y., Otani, S., and Grace, A. A. (2007). The Yin and Yang of dopamine release: a new perspective. Neuropharmacology 53, 583-587. doi: 10.1016/j.neuropharm.2007.07.007

Grace, A. A. (1991). Phasic versus tonic dopamine release and the modulation of dopamine system responsivity: a hypothesis for the etiology of schizophrenia. Neuroscience 41, 1-24. doi: 10.1016/0306-4522(91) 90196-U
Grace, A. A., and Bunney, B. S. (1984). The control of firing pattern in nigral dopamine neurons: burst firing. J. Neurosci. 4, 2877-2890.

Graybiel, A. M. (2008). Habits, rituals, and the evaluative brain. Annu. Rev. Neurosci. 31, 359-387. doi: 10.1146/annurev.neuro.29.051605.112851

Gulledge, A. T., and Jaffe, D. B. (1998). Dopamine decreases the excitability of layer V pyramidal cells in the rat prefrontal cortex. J. Neurosci. 18, 9139-9151.

Gulledge, A. T., and Jaffe, D. B. (2001). Multiple effects of dopamine on layer V pyramidal cell excitability in rat prefrontal cortex. J. Neurophysiol. 86, 586-595.

Güntürkün, O. (1997). Cognitive impairments after lesions of the neostriatum caudolaterale and its thalamic afferent in pigeons: functional similarities to the mammalian prefrontal system? J. Hirnforsch. 38, 133-143.

Güntürkün, O. (2005a). Avian and mammalian "prefrontal cortices”: limited degrees of freedom in the evolution of the neural mechanisms of goal-state maintenance. Brain Res. Bull. 66, 311-316. doi: 10.1016/j.brainresbull.2005. 02.004

Güntürkün, O. (2005b). The avian "prefrontal cortex" and cognition. Curr. Opin. Neurobiol. 15, 686-693. doi: 10.1016/j.conb.2005.10.003

Güntürkün, O. (2012). The convergent evolution of neural substrates for cognition. Psychol. Res. 76, 212-219. doi: 10.1007/s00426-011-0377-9

Hara, E., Kubikova, L., Hessler, N. A., and Jarvis, E. D. (2007). Role of the midbrain dopaminergic system in modulation of vocal brain activation by social context. Eur. J. Neurosci. 25, 3406-3416. doi: 10.1111/j.1460-9568.2007.05600.x

Hazy, T. E., Frank, M. J., and O'reilly, R. C. (2007). Towards an executive without a homunculus: computational models of the prefrontal cortex/basal ganglia system. Philos. Trans. R. Soc. Lond. B Biol. Sci. 362, 1601-1613. doi: 10.1098/rstb.2007.2055

Henze, D. A., González-Burgos, G. R., Urban, N. N., Lewis, D. A., and Barrionuevo, G. (2000). Dopamine increases excitability of pyramidal neurons in primate prefrontal cortex. J. Neurophysiol. 84, 2799-2809.

Herold, C., Diekamp, B., and Güntürkün, O. (2008). Stimulation of dopamine D1 receptors in the avian fronto-striatal system adjusts daily cognitive fluctuations. Behav. Brain Res. 194, 223-229. doi: 10.1016/j.bbr.2008.07.017

Herold, C., Joshi, I., Chehadi, O., Hollmann, M., and Güntürkün, O. (2012). Plasticity in D1-like receptor expression is associated with different components of cognitive processes. PLoS ONE 7:e36484. doi: 10.1371/journal.pone.0036484

Histed, M. H., Pasupathy, A., and Miller, E. K. (2009). Learning substrates in the primate prefrontal cortex and striatum: sustained activity related to successful actions. Neuron 63, 244-253. doi: 10.1016/j.neuron.2009. 06.019

Honig, W. K. (1978). "Studies of working memory in the pigeon," in Cognitive Processes in Animal Behavior (New York: Hillsdale), 211-248.

Horvitz, J. C. (2000). Mesolimbocortical and nigrostriatal dopamine responses to salient non-reward events. Neuroscience 96, 651-656. doi: 10.1016/S03064522(00)00019-1

Howe, M. W., Tierney, P. L., Sandberg, S. G., Phillips, P. E. M., and Graybiel, A. M. (2013). Prolonged dopamine signalling in striatum signals proximity and value of distant rewards. Nature 500, 575-579. doi: 10.1038/ nature 12475

Humphries, M. D., Khamassi, M., and Gurney, K. (2012). Dopaminergic control of the exploration-exploitation trade-off via the basal ganglia. Front. Neurosci. 6:9. doi: 10.3389/fnins.2012.00009

Ilango, A., Kesner, A. J., Keller, K. L., Stuber, G. D., Bonci, A., and Ikemoto, S. (2014). Similar roles of substantia nigra and ventral tegmental dopamine neurons in reward and aversion. J. Neurosci. 34, 817-822. doi: 10.1523/JNEUROSCI.170313.2014

Ingvar, D. H., and Franzén, G. (1974). Abnormalities of cerebral blood flow distribution in patients with chronic schizophrenia. Acta Psychiatr. Scand. 50, 425-462. doi: 10.1111/j.1600-0447.1974.tb09707.x

Jarvis, E. D. (2009). "Evolution of the pallium in birds and reptiles," in New Encyclopedia of Neuroscience, ed. A. B. Butler (New York: Elsevier), 15.

Jarvis, E. D., Güntürkün, O., Bruce, L., Csillag, A., Karten, H., Kuenzel, W., et al. (2005). Avian brains and a new understanding of vertebrate brain evolution. Nat. Rev. Neurosci. 6, 151-159. doi: 10.1038/nrn1606

Jarvis, E. D., Yu, J., Rivas, M. V., Horita, H., Feenders, G., Whitney, O., et al. (2013). Global view of the functional molecular organization of the avian cerebrum: mirror images and functional columns. J. Comp. Neurol. 521, 3614-3665. doi: $10.1002 /$ cne. 23404 
Jo, Y. S., Lee, J., and Mizumori, S. J. Y. (2013). Effects of prefrontal cortical inactivation on neural activity in the ventral tegmental area. J. Neurosci. 33, 8159-8171. doi: 10.1523/JNEUROSCI.0118-13.2013

Joshua, M., Adler, A., Mitelman, R., Vaadia, E., and Bergman, H. (2008). Midbrain dopaminergic neurons and striatal cholinergic interneurons encode the difference between reward and aversive events at different epochs of probabilistic classical conditioning trials. J. Neurosci. 28, 11673-11684. doi 10.1523/JNEUROSCI.3839-08.2008

Kalenscher, T., Windmann, S., Diekamp, B., Rose, J., Güntürkün, O., and Colombo, M. (2005). Single units in the pigeon brain integrate reward amount and time-to-reward in an impulsive choice task. Curr. Biol. 15, 594-602. doi: 10.1016/j.cub.2005.02.052

Kalkstein, S., Hurford, I., and Gur, R. C. (2010). "Neurocognition in schizophrenia," in Behavioral Neurobiology of Schizophrenia and Its Treatment Current Topics in Behavioral Neurosciences, ed. N. R. Swerdlow (Berlin Heidelberg: Springer), 373 390. doi: 10.1007/7854_2010_42

Karakuyu, D., Herold, C., Güntürkün, O., and Diekamp, B. (2007). Differential increase of extracellular dopamine and serotonin in the "prefrontal cortex" and striatum of pigeons during working memory. Eur. J. Neurosci. 26, 2293-2302. doi: 10.1111/j.1460-9568.2007.05840.x

Kehagia, A. A., Barker, R. A., and Robbins, T. W. (2010). Neuropsychological and clinical heterogeneity of cognitive impairment and dementia in patients with Parkinson's disease. Lancet Neurol. 9, 1200-1213. doi: 10.1016/S14744422(10)70212-X

Kellendonk, C., Simpson, E. H., Polan, H. J., Malleret, G., Vronskaya, S., Winiger, V., etal. (2006). Transient and selective overexpression of dopamine D2 receptors in the striatum causes persistent abnormalities in prefrontal cortex functioning. Neuron 49, 603-615. doi: 10.1016/j.neuron.2006. 01.023

Kimberg, D. Y., D’Esposito, M., and Farah, M. J. (1997). Effects of bromocriptine on human subjects depend on working memory capacity. Neuroreport 8, 3581-3585. doi: 10.1097/00001756-199711100-00032

Kirsch, J. A., Güntürkün, O., and Rose, J. (2008). Insight without cortex: lessons from the avian brain. Conscious. Cogn. 17, 475-483. doi: 10.1016/j.concog.2008. 03.018

Kirsch, J. A., Vlachos, I., Hausmann, M., Rose, J., Yim, M. Y., Aertsen, A., et al. (2009). Neuronal encoding of meaning: establishing category-selective response patterns in the avian "prefrontal cortex." Behav. Brain Res. 198, 214-223. doi: 10.1016/j.bbr.2008.11.010

Kravitz, A. V., Tye, L. D., and Kreitzer, A. C. (2012). Distinct roles for direct and indirect pathway striatal neurons in reinforcement. Nat. Neurosci. 15, 816-818. doi: 10.1038/nn.3100

Kröner, S., and Güntürkün, O. (1999). Afferent and efferent connections of the caudolateral neostriatum in the pigeon (Columba livia): a retro- and anterograde pathway tracing study. J. Comp. Neurol. 407, 228-260. doi: 10.1002/(SICI)10969861(19990503)407:2<228::AID-CNE6>3.0.CO;2-2

Kubikova, L., Wada, K., and Jarvis, E. D. (2010). Dopamine receptors in a songbird brain. J. Comp. Neurol. 518, 741-769. doi: 10.1002/ cne. 22255

Lammel, S., Lim, B. K., Ran, C., Huang, K. W., Betley, M. J., Tye, K. M., etal. (2012). Input-specific control of reward and aversion in the ventral tegmental area. Nature 491, 212-217. doi: 10.1038/ nature 11527

Lange, K. W., Robbins, T. W., Marsden, C. D., James, M., Owen, A. M., and Paul, G. M. (1992). L-dopa withdrawal in Parkinson's disease selectively impairs cognitive performance in tests sensitive to frontal lobe dysfunction. Psychopharmacology (Berl.) 107, 394-404. doi: 10.1007/ BF02245167

Lataster, J., Collip, D., Ceccarini, J., Haas, D., Booij, L., van Os, J., etal. (2011). Psychosocial stress is associated with in vivo dopamine release in human ventromedial prefrontal cortex: a positron emission tomography study using [18F]fallypride. Neuroimage 58, 1081-1089. doi: 10.1016/j.neuroimage.2011.07.030

Lauzon, N. M., Bishop, S. F., and Laviolette, S. R. (2009). Dopamine D1 versus D4 receptors differentially modulate the encoding of salient versus nonsalient emotional information in the medial prefrontal cortex. J. Neurosci. 29, 4836-4845. doi: 10.1523/JNEUROSCI.017809.2009
Lavin, A., Nogueira, L., Lapish, C. C., Wightman, R. M., Phillips, P. E. M., and Seamans, J. K. (2005). Mesocortical dopamine neurons operate in distinct temporal domains using multimodal signaling. J. Neurosci. 25, 5013-5023. doi: 10.1523/JNEUROSCI.055705.2005

Laviolette, S. R., Lipski, W. J., and Grace, A. A. (2005). A subpopulation of neurons in the medial prefrontal cortex encodes emotional learning with burst and frequency codes through a dopamine D4 receptor-dependent basolateral amygdala input. J. Neurosci. 25, 6066-6075. doi: 10.1523/JNEUROSCI.1168-05.2005

Lee, B., Groman, S., London, E. D., and Jentsch, J. D. (2007). Dopamine D2/D3 receptors play a specific role in the reversal of a learned visual discrimination in monkeys. Neuropsychopharmacology 32, 2125-2134. doi: 10.1038/sj.npp.1301337

Lee, T., Cai, L. X., Lelyveld, V. S., Hai, A., and Jasanoff, A. (2014). Molecular-level functional magnetic resonance imaging of dopaminergic signaling. Science 344, 533-535. doi: 10.1126/science. 1249380

Lewis, D. A., and Sesack, S. R. (1997). “Chapter VI: dopamine systems in the primate brain," in Handbook of Chemical Neuroanatomy, Vol. 15, The Primate Nervous System, Part I, eds F. E. Bloom, A. Björklund, and T. Hökfelt (Amsterdam: Elsevier), 263-375. doi: 10.1016/S0924-8196(97)80008-5

Li, Y. C., Kellendonk, C., Simpson, E. H., Kandel, E. R., and Gao, W. J. (2011). D2 receptor overexpression in the striatum leads to a deficit in inhibitory transmission and dopamine sensitivity in mouse prefrontal cortex. Proc. Natl. Acad. Sci. U.S.A. 108, 12107-12112. doi: 10.1073/pnas.1109718108

Lidow, M. S., Goldman-Rakic, P. S., Gallager, D. W., and Rakic, P. (1991). Distribution of dopaminergic receptors in the primate cerebral cortex: quantitative autoradiographic analysis using $[3 \mathrm{H}]$ raclopride, $[3 \mathrm{H}]$ spiperone and [3H]SCH23390. Neuroscience 40, 657-671. doi: 10.1016/0306-4522(91)90003-7

Lindvall, O., Björklund, A., and Divac, I. (1978). Organization of catecholamine neurons projecting to the frontal cortex in the rat. Brain Res. 142, 1-24. doi: 10.1016/0006-8993(78)90173-7

Luciana, M., and Collins, P. F. (1997). Dopaminergic modulation of working memory for spatial but not object cues in normal humans. J. Cogn. Neurosci. 9, 330-347. doi: 10.1162/jocn.1997.9.3.330

Malhotra, A. K., Kestler, L. J., Mazzanti, C., Bates, J. A., Goldberg, T., and Goldman, D. (2002). A functional polymorphism in the COMT gene and performance on a test of prefrontal cognition. Am. J. Psychiatry 159, 652-654. doi: 10.1176/appi.ajp.159.4.652

Mante, V., Sussillo, D., Shenoy, K. V., and Newsome, W. T. (2013). Contextdependent computation by recurrent dynamics in prefrontal cortex. Nature 503, 78-84. doi: 10.1038/nature12742

Matsumoto, M., and Hikosaka, O. (2009). Two types of dopamine neuron distinctly convey positive and negative motivational signals. Nature 459, 837-841. doi: 10.1038/nature08028

Mattay, V. S., Tessitore, A., Callicott, J. H., Bertolino, A., Goldberg, T. E., Chase, T. N., et al. (2002). Dopaminergic modulation of cortical function in patients with Parkinson's disease. Ann. Neurol. 51, 156-164. doi: 10.1002/ana.10078

Miller, E. K., Erickson, C. A., and Desimone, R. (1996). Neural mechanisms of visual working memory in prefrontal cortex of the macaque. J. Neurosci. 16, 5154-5167.

Mizoguchi, K., Shoji, H., Tanaka, Y., Maruyama, W., and Tabira, T. (2009). Age-related spatial working memory impairment is caused by prefrontal cortical dopaminergic dysfunction in rats. Neuroscience 162, 1192-1201. doi: 10.1016/j.neuroscience. 2009. 05.023

Mizumori, S. J., Channon, V., Rosenzweig, M. R., and Bennett, E. L. (1987). Shortand long-term components of working memory in the rat. Behav. Neurosci. 101, 782-789. doi: 10.1037/0735-7044.101.6.782

Mogensen, J., and Divac, I. (1982). The prefrontal "cortex" in the pigeon. Behavioral evidence Brain Behav. Evol. 21, 60-66. doi: 10.1159/ 000121617

Morris, G., Arkadir, D., Nevet, A., Vaadia, E., and Bergman, H. (2004). Coincident but distinct messages of midbrain dopamine and striatal tonically active neurons. Neuron 43, 133-143. doi: 10.1016/j.neuron.2004.06.012

Morris, G., Nevet, A., Arkadir, D., Vaadia, E., and Bergman, H. (2006). Midbrain dopamine neurons encode decisions for future action. Nat. Neurosci. 9, 10571063. doi: $10.1038 / \mathrm{nn} 1743$

Morris, G., Schmidt, R., and Bergman, H. (2010). Striatal action-learning based on dopamine concentration. Exp. Brain Res. 200, 307-317. doi: 10.1007/s00221-0092060-6 
Moustafa, A. A., and Gluck, M. A. (2011). Computational cognitive models of prefrontal-striatal-hippocampal interactions in Parkinson's disease and schizophrenia. Neural Netw. 24, 575-591. doi: 10.1016/j.neunet.2011. 02.006

Müller, U., von Cramon, D. Y., and Pollmann, S. (1998). D1- versus D2-receptor modulation of visuospatial working memory in humans. J. Neurosci. 18, 2720 2728.

Murphy, B. L., Arnsten, A. F., Goldman-Rakic, P. S., and Roth, R. H. (1996). Increased dopamine turnover in the prefrontal cortex impairs spatial working memory performance in rats and monkeys. Proc. Natl. Acad. Sci. U.S.A. 93, 1325-1329. doi: 10.1073/pnas.93.3.1325

Narayanan, N. S., Rodnitzky, R. L., and Uc, E. (2013). Prefrontal dopamine signaling and cognitive symptoms of Parkinson's Disease. Rev. Neurosci. 24, 267-278. doi: 10.1515/revneuro-2013-0004

O'Reilly, R. C., and Frank, M. J. (2006). Making working memory work: a computational model of learning in the prefrontal cortex and basal ganglia. Neural Comput. 18, 283-328. doi: 10.1162/089976606775093909

O’Reilly, R. C., Noelle, D. C., Braver, T. S., and Cohen, J. D. (2002). Prefrontal cortex and dynamic categorization tasks: representational organization and neuromodulatory control. Cereb. Cortex 12, 246-257. doi: 10.1093/cercor/ 12.3.246

Okubo, Y., Suhara, T., Suzuki, K., Kobayashi, K., Inoue, O., Terasaki, O., et al. (1997). Decreased prefrontal dopamine D1 receptors in schizophrenia revealed by PET Nature 385, 634-636. doi: 10.1038/385634a0

Olver, J. S., Pinney, M., Maruff, P., and Norman, T. R. (2014). Impairments of spatial working memory and attention following acute psychosocial stress. Stress Health doi: 10.1002/smi.2533 [Epub ahead of print].

Pan, W.-X., Schmidt, R., Wickens, J. R., and Hyland, B. I. (2005). Dopamine cells respond to predicted events during classical conditioning: evidence for eligibility traces in the reward-learning network. J. Neurosci. 25, 6235-6242. doi: 10.1523/JNEUROSCI.1478-05.2005

Pan, W.-X., Schmidt, R., Wickens, J. R., and Hyland, B. I. (2008). Tripartite mechanism of extinction suggested by dopamine neuron activity and temporal difference model. J. Neurosci. 28, 9619-9631. doi: 10.1523/JNEUROSCI.025508.2008

Parush, N., Tishby, N., and Bergman, H. (2011). Dopaminergic balance between reward maximization and policy complexity. Front. Syst. Neurosci. 5:22. doi: 10.3389/fnsys.2011.00022

Pasupathy, A., and Miller, E. K. (2005). Different time courses of learningrelated activity in the prefrontal cortex and striatum. Nature 433, 873-876. doi: 10.1038/nature03287

Phillips, A. G., Ahn, S., and Floresco, S. B. (2004). Magnitude of dopamine release in medial prefrontal cortex predicts accuracy of memory on a delayed response task. J. Neurosci. 24, 547-553. doi: 10.1523/JNEUROSCI.465303.2004

Phillips, P. E. M., Stuber, G. D., Heien, M. L. A. V., Wightman, R. M., and Carelli, R. M. (2003). Subsecond dopamine release promotes cocaine seeking. Nature 422, 614-618. doi: 10.1038/nature01476

Puig, M. V., and Miller, E. K. (2012). The role of prefrontal dopamine D1 receptors in the neural mechanisms of associative learning. Neuron 74, 874-886. doi: 10.1016/j.neuron.2012.04.018

Puig, M. V., and Miller, E. K. (2014). Neural substrates of dopamine D2 receptor modulated executive functions in the monkey prefrontal cortex. Cereb. Cortex doi: 10.1093/cercor/bhu096 [Epub ahead of print].

Ramayya, A. G., Misra, A., Baltuch, G. H., and Kahana, M. J. (2014). Microstimulation of the human substantia nigra alters reinforcement learning. J. Neurosci. 34, 6887-6895. doi: 10.1523/JNEUROSCI.5445-13.2014

Redgrave, P., Gurney, K., and Reynolds, J. (2008). What is reinforced by phasic dopamine signals? Brain Res. Rev. 58, 322-339. doi: 10.1016/j.brainresrev.2007.10.007

Reiner, A., Yamamoto, K., and Karten, H. J. (2005). Organization and evolution of the avian forebrain. Anat. Rec. A Discov. Mol. Cell. Evol. Biol. 287A, 1080-1102. doi: 10.1002/ar.a.20253

Rieke, G. K. (1980). Kainic acid lesions of pigeon paleostriatum: a model for study of movement disorders. Physiol. Behav. 24, 683-687. doi: 10.1016/00319384(80)90397-2

Rieke, G. K. (1981). Movement disorders and lesions of pigeon brain stem analogues of basal ganglia. Physiol. Behav. 26, 379-384. doi: 10.1016/0031-9384(81)90162-1
Rigotti, M., Barak, O., Warden, M. R., Wang, X.-J., Daw, N. D., Miller, E. K., et al. (2013). The importance of mixed selectivity in complex cognitive tasks. Nature 497, 585-590. doi: 10.1038/nature 12160

Robbins, T. W. (2000). Chemical neuromodulation of frontal-executive functions in humans and other animals. Exp. Brain Res. 133, 130-138. doi: 10.1007/s002210000407

Robbins, T. W., and Roberts, A. C. (2007). Differential regulation of fronto-executive function by the monoamines and acetylcholine. Cereb. Cortex 17, i151-i160. doi: $10.1093 /$ cercor/bhm066

Rose, J., and Colombo, M. (2005). Neural correlates of executive control in the avian brain. PLoS Biol. 3:e190. doi: 10.1371/journal.pbio.0030190

Rose, J., Güntürkün, O., and Kirsch, J. (2009a). "Evolution of association pallial areas: in birds," in Encyclopedia of Neuroscience, eds M. D. Binder, N. Hirokawa, and U. Windhorst (Berlin, Heidelberg: Springer), 1215-1219.

Rose, J., Schmidt, R., Grabemann, M., and Güntürkün, O. (2009b). Theory meets pigeons: the influence of reward-magnitude on discrimination-learning. Behav. Brain Res. 198, 125-129. doi: 10.1016/j.bbr.2008.10.038

Rose, J., Schiffer, A.-M., Dittrich, L., and Güntürkün, O. (2010). The role of dopamine in maintenance and distractability of attention in the "prefrontal cortex" of pigeons. Neuroscience 167, 232-237. doi: 10.1016/j.neuroscience.2010.02.004

Rose, J., Schiffer, A.-M., and Güntürkün, O. (2013). Striatal dopamine D1 receptors are involved in the dissociation of learning based on rewardmagnitude. Neuroscience 230, 132-138. doi: 10.1016/j.neuroscience.2012. 10.064

Rosenberg, D. R., and Lewis, D. A. (1994). Changes in the dopaminergic innervation of monkey prefrontal cortex during late postnatal development: a tyrosine hydroxylase immunohistochemical study. Biol. Psychiatry 36, 272-277. doi: 10.1016/0006-3223(94)90610-6

Rothmond, D. A., Weickert, C. S., and Webster, M. J. (2012). Developmental changes in human dopamine neurotransmission: cortical receptors and terminators. $B M C$ Neurosci. 13:18. doi: 10.1186/1471-2202-13-18

Šagud, M., Mück-Šeler, D., Mihaljević-PeleŠ, A., Vuksan-ćusa, B., Živković, M., Jakovljević, M., et al. (2010). Catechol-O-methyl transferase and schizophrenia. Psychiatr. Danub. 22, 270-274.

Santana, N., Mengod, G., and Artigas, F. (2009). Quantitative analysis of the expression of dopamine D1 and D2 receptors in pyramidal and GABAergic neurons of the rat prefrontal cortex. Cereb. Cortex 19, 849-860. doi: 10.1093/cercor/ bhn 134

Sawaguchi, T., and Goldman-Rakic, P. S. (1991). D1 dopamine receptors in prefrontal cortex: involvement in working memory. Science 22, 947-950. doi: $10.1126 /$ science. 1825731

Sawaguchi, T., and Goldman-Rakic, P. S. (1994). The role of D1-dopamine receptor in working memory: local injections of dopamine antagonists into the prefrontal cortex of rhesus monkeys performing an oculomotor delayed-response task. J. Neurophysiol. 71, 515-528.

Scatton, B., Javoy-Agid, F., Rouquier, L., Dubois, B., and Agid, Y. (1983). Reduction of cortical dopamine, noradrenaline, serotonin and their metabolites in Parkinson's disease. Brain Res. 275, 321-328. doi: 10.1016/0006-8993(83) 90993-9

Schultz, W. (1997). Dopamine neurons and their role in reward mechanisms. Curr. Opin. Neurobiol. 7, 191-197. doi: 10.1016/S0959-4388(97) 80007-4

Schultz, W. (1998). Predictive reward signal of dopamine neurons. J. Neurophysiol. $80,1-27$.

Schultz, W. (2002). Getting formal with dopamine and reward. Neuron 36, 241-263. doi: 10.1016/S0896-6273(02)00967-4

Schultz, W. (2007). Multiple dopamine functions at different time courses. Annu. Rev. Neurosci. 30, 259-288. doi: 10.1146/annurev.neuro.28.061604. 135722

Schultz, W. (2013). Updating dopamine reward signals. Curr. Opin. Neurobiol. 23, 229-238. doi: 10.1016/j.conb.2012.11.012

Schultz, W., Apicella, P., and Ljungberg, T. (1993). Responses of monkey dopamine neurons to reward and conditioned stimuli during successive steps of learning a delayed response task. J. Neurosci. 13, 900-913.

Seamans, J. K., Floresco, S. B., and Phillips, A. G. (1998). D1 receptor modulation of hippocampal-prefrontal cortical circuits integrating spatial memory with executive functions in the rat. J. Neurosci. 18, 1613-1621. 
Seamans, J. K., and Yang, C. R. (2004). The principal features and mechanisms of dopamine modulation in the prefrontal cortex. Prog. Neurobiol. 74, 1-58. doi: 10.1016/j.pneurobio.2004.05.006

Seeman, P. (1987). Dopamine receptors and the dopamine hypothesis of schizophrenia. Synapse 1, 133-152. doi: 10.1002/syn.890010203

Seidman, L. J., Valera, E. M., and Makris, N. (2005). Structural brain imaging of attention-deficit/hyperactivity disorder. Biol. Psychiatry 57, 1263-1272. doi: 10.1016/j.biopsych.2004.11.019

Seong, H. J., and Carter, A. G. (2012). D1 receptor modulation of action potential firing in a subpopulation of layer 5 pyramidal neurons in the prefrontal cortex. $J$. Neurosci. 32, 10516-10521. doi: 10.1523/JNEUROSCI.1367-12.2012

Servan-Schreiber, D., Printz, H., and Cohen, J. D. (1990). A network model of catecholamine effects: gain, signal-to-noise ratio, and behavior. Science 249, 892 895. doi: 10.1126/science. 2392679

Shanahan, M., Bingman, V. P., Shimizu, T., Wild, M., and Güntürkün, O. (2013). Large-scale network organization in the avian forebrain: a connectivity matrix and theoretical analysis. Front. Comput. Neurosci. 7:89. doi: 10.3389/fncom.2013.00089

Sheynikhovich, D., Otani, S., and Arleo, A. (2013). Dopaminergic control of long-term depression/long-term potentiation threshold in prefrontal cortex. $J$. Neurosci. 33, 13914-13926. doi: 10.1523/JNEUROSCI.0466-13.2013

Simon, H. (1981). Dopaminergic A10 neurons and the frontal system. J. Physiol. 77, 81-95.

Simonyan, K., Horwitz, B., and Jarvis, E. D. (2012). Dopamine regulation of human speech and bird song: a critical review. Brain Lang. 122, 142-150. doi: 10.1016/j.bandl.2011.12.009

Smith, Y., Bevan, M. D., Shink, E., and Bolam, J. P. (1998). Microcircuitry of the direct and indirect pathways of the basal ganglia. Neuroscience 86, 353-387.

Sutton, R. S. (1998). Reinforcement Learning: An Introduction. Cambridge, MA: MIT Press.

Swanson, L. W. (1982). The projections of the ventral tegmental area and adjacent regions: a combined fluorescent retrograde tracer and immunofluorescence study in the rat. Brain Res. Bull. 9, 321-353. doi: 10.1016/0361-9230(82)90145-9

Takahashi, H., Kato, M., Takano, H., Arakawa, R., Okumura, M., Otsuka, T., et al. (2008). Differential contributions of prefrontal and hippocampal dopamine D1 and D2 receptors in human cognitive functions. J. Neurosci. 28, 12032-12038. doi: 10.1523/JNEUROSCI.3446-08.2008

Takahashi, Y. K., Roesch, M. R., Wilson, R. C., Toreson, K., O’Donnell, P., Niv, Y., et al. (2011). Expectancy-related changes in firing of dopamine neurons depend on orbitofrontal cortex. Nat. Neurosci. 14, 1590-1597. doi: 10.1038/ nn. 2957

Thierry, A. M., Blanc, G., Sobel, A., Stinus, L., and Golwinski, J. (1973). Dopaminergic terminals in the rat cortex. Science 182, 499-501. doi: 10.1126/science.182.4111.499

Thompson, J. L., Rosell, D. R., Slifstein, M., Girgis, R. R., Xu, X., Ehrlich, Y., et al. (2014). Prefrontal dopamine D1 receptors and working memory in schizotypal personality disorder: a PET study with [(11)C]NNC112. Psychopharmacology (Berl.) doi: 10.1007/s00213-014-3566-6 [Epub ahead of print].

Tobler, P. N., Dickinson, A., and Schultz, W. (2003). Coding of predicted reward omission by dopamine neurons in a conditioned inhibition paradigm. J. Neurosci. 23, 10402-10410.

Tseng, K. Y., and O’Donnell, P. (2004). Dopamine-glutamate interactions controlling prefrontal cortical pyramidal cell excitability involve multiple signaling mechanisms. J. Neurosci. 24, 5131-5139. doi: 10.1523/JNEUROSCI.102104.2004

Veit, L., Hartmann, K., and Nieder, A. (2014). Neuronal correlates of visual working memory in the corvid endbrain. J. Neurosci. 34, 7778-7786. doi: 10.1523/JNEUROSCI.0612-14.2014

Veit, L., and Nieder, A. (2013). Abstract rule neurons in the endbrain support intelligent behaviour in corvid songbirds. Nat. Commun. 4, 2878. doi: $10.1038 /$ ncomms 3878

Vereczkei, A., and Mirnics, K. (2011). Genetic predisposition to schizophrenia: what did we learn and what does the future hold? Neuropsychopharmacol. Hung. 13, 205-210.
Vijayraghavan, S., Wang, M., Birnbaum, S. G., Williams, G. V., and Arnsten, A. F. T. (2007). Inverted-U dopamine D1 receptor actions on prefrontal neurons engaged in working memory. Nat. Neurosci. 10, 376-384. doi: 10.1038/nn1846

Waldmann, C., and Güntürkün, O. (1993). The dopaminergic innervation of the pigeon caudolateral forebrain: immunocytochemical evidence for a "prefrontal cortex" in birds? Brain Res. 600, 225-234. doi: 10.1016/0006-8993(93)91377-5

Walker, S. C., Robbins, T. W., and Roberts, A. C. (2009). Differential contributions of dopamine and serotonin to orbitofrontal cortex function in the marmoset. Cereb. Cortex 19, 889-898. doi: 10.1093/cercor/ bhn 136

Wallis, J. D., Anderson, K. C., and Miller, E. K. (2001). Single neurons in prefrontal cortex encode abstract rules. Nature 411, 953-956. doi: 10.1038/ 35082081

Wang, M., Vijayraghavan, S., and Goldman-Rakic, P. S. (2004). Selective D2 receptor actions on the functional circuitry of working memory. Science 303, 853-856. doi: 10.1126/science.1091162

Watabe-Uchida, M., Zhu, L., Ogawa, S. K., Vamanrao, A., and Uchida, N. (2012). Whole-brain mapping of direct inputs to midbrain dopamine neurons. Neuron 74, 858-873. doi: 10.1016/j.neuron.2012.03.017

Watanabe, M., Kodama, T., and Hikosaka, K. (1997). Increase of extracellular dopamine in primate prefrontal cortex during a working memory task. J. Neurophysiol. 78, 2795-2798.

Wickens, J. R., Horvitz, J. C., Costa, R. M., and Killcross, S. (2007). Dopaminergic mechanisms in actions and habits. J. Neurosci. 27, 8181-8183. doi: 10.1523/JNEUROSCI.1671-07.2007

Williams, G. V., and Castner, S. A. (2006). Under the curve: critical issues for elucidating D1 receptor function in working memory. Neuroscience 139, 263-276. doi: 10.1016/j.neuroscience.2005.09.028

Williams, G. V., and Goldman-Rakic, P. S. (1995). Modulation of memory fields by dopamine D1 receptors in prefrontal cortex. Nature 376, 572-575. doi: $10.1038 / 376572 \mathrm{a} 0$

Wynne, B., and Güntürkün, O. (1995). Dopaminergic innervation of the telencephalon of the pigeon (Columba livia): a study with antibodies against tyrosine hydroxylase and dopamine. J. Comp. Neurol. 357, 446-464. doi: $10.1002 /$ cne.903570309

Yanagihara, S., and Hessler, N. A. (2006). Modulation of singingrelated activity in the songbird ventral tegmental area by social context. Eur. J. Neurosci. 24, 3619-3627. doi: 10.1111/j.1460-9568.2006. 05228.x

Yang, C. R., and Seamans, J. K. (1996). Dopamine D1 receptor actions in layers V-VI rat prefrontal cortex neurons in vitro: modulation of dendritic-somatic signal integration. J. Neurosci. 16, 1922-1935.

Zahrt, J., Taylor, J. R., Mathew, R. G., and Arnsten, A. F. (1997). Supranormal stimulation of D1 dopamine receptors in the rodent prefrontal cortex impairs spatial working memory performance. J. Neurosci. 17, 8528-8535.

Zipser, D., Kehoe, B., Littlewort, G., and Fuster, J. (1993). A spiking network model of short-term active memory. J. Neurosci. 13, 3406-3420.

Conflict of Interest Statement: The authors declare that the research was conducted in the absence of any commercial or financial relationships that could be construed as a potential conflict of interest.

Received: 31 May 2014; accepted: 18 July 2014; published online: 05 August 2014. Citation: Puig MV, Rose J, Schmidt R and Freund N (2014) Dopamine modulation of learning and memory in the prefrontal cortex: insights from studies in primates, rodents, and birds. Front. Neural Circuits 8:93. doi: 10.3389/fncir.2014.00093 This article was submitted to the journal Frontiers in Neural Circuits.

Copyright (c) 2014 Puig, Rose, Schmidt and Freund. This is an open-access article distributed under the terms of the Creative Commons Attribution License (CC BY). The use, distribution or reproduction in other forums is permitted, provided the original author(s) or licensor are credited and that the original publication in this journal is cited, in accordance with accepted academic practice. No use, distribution or reproduction is permitted which does not comply with these terms. 